\title{
Contributions of nature-based solutions to reduce peoples' vulnerabilities to climate change across the rural Global South
}

Authors: Stephen Woroniecki ${ }^{1,2}$, Femke A. Spiegelenberg ${ }^{1}$, Alexandre Chausson ${ }^{2}$, Beth Turner ${ }^{2,3}$, Isabel Key $^{1,4}$, Haseeb Md. Irfanullah ${ }^{5}$, Nathalie Seddon ${ }^{2}$

1. Linköping University, Department of Thematic Studies, Environmental Change Unit, Sweden

2. Nature-based Solutions Initiative. Department of Zoology, University of Oxford, Oxford OX1 3PS, United Kingdom

3. Centre d'Étude de la Forêt, Département Des Sciences Biologiques, Université Du Québec à Montréal, Montréal, QC, Canada

4. Changing Oceans Group, School of GeoSciences, University of Edinburgh, Edinburgh, UK

5. Haseeb Md. Irfanullah: Center for Sustainable Development, University of Liberal Arts Bangladesh (ULAB), Dhanmondi, Dhaka, Bangladesh

Corresponding author email: stephen.woroniecki@liu.se; Postal Address: Linköping University,

Department of Thematic Studies/Environmental Change, 58183 Linköping, Sweden

Abstract: Nature-based solutions (NbS) -i.e. working with and enhancing nature to address societal challenges - feature with increasing prominence in responses to climate change, including in the adaptation plans of the most vulnerable nations. Although evidence for the effectiveness of NbS for adaptation is growing, there is less evidence on whether and how NbS reduce vulnerability to climate change in the Global South, despite this region being home to most of the world's most climatevulnerable people. To address this, we analysed the vulnerability-reduction outcomes of 85 naturebased interventions in rural areas across the Global South, and factors mediating their effectiveness, based on a systematic map of peer-reviewed studies encompassing a wide diversity of ecosystems, climate impacts, intervention types and institutions. We applied an analytical framework based on social-ecological systems and climate change vulnerability, coding studies with respect to six pathways of vulnerability reduction: social and ecological exposure, sensitivity, and adaptive capacity. We find widespread effectiveness of $\mathrm{NbS}$ in the dataset with $95 \%$ providing positive outcomes for climate change adaptation. Overall, nature-based interventions reduced vulnerability primarily by lowering ecosystem sensitivity to climate impacts ( $73 \%$ of interventions), followed by reducing social sensitivity $(43 \%)$, reducing ecological exposure (37\%), and/or increasing social adaptive capacity (34\%), ecological adaptive capacity $(18 \%)$ and reducing social exposure $(12 \%)$. With an analysis of mediating factors, we show that vulnerability-reduction effectiveness was affected as much by social and political factors as by technical considerations. Indeed configurations of existing and introduced formal and informal institutions appear central to the efficacy and distributive effects of the studied interventions. We conclude that attention to the distinct pathways through which vulnerability is reduced can help maximise the benefits of $\mathrm{NbS}$ and that to be successful, careful consideration is required on their applicability to particular circumstances as well as their social dimensions.

Keywords: Nature-based solutions, climate change adaptation, climate change vulnerability, social-

ecological systems 


\section{INTRODUCTION}

Around the world people are already suffering from the impacts of climate change (IPCC AR6 forthcoming), with the poorest communities worst hit across a range of outcomes and severely impeding development (Olsson et al., 2014; Paavola and Adger, 2006; Roy et al., 2018). Consequently, there is an urgent need to develop effective approaches to adaptation that address the needs and priorities of those most at-risk.

Nature-based solutions (NbS) are being widely hailed as having the potential to provide effective approaches to climate change impacts, especially in the global south (Munang et al., 2014; Jones et al., 2015; Seddon et al., 2020a).

$\mathrm{NbS}$, herein defined as approaches that work with and enhance nature in order to address societal challenges (Chausson, Turner et al., 2020), are receiving much attention at the highest scientific and policy levels and feature prominently in Global Environmental Assessments (IPCC AR6 forthcoming, IPBES, 2019, IPCC SRCCL, IPCC SR1.5; Seddon et al 2021). One reason for this is growing evidence that $\mathrm{NbS}$ can address multiple, interacting societal challenges such as climate change, biodiversity loss and other sustainable development goals (Pörtner et al., 2021) with potentially fewer tradeoffs for mitigation and development (Smith et al., 2021).

Nature-based approaches for adaptation, especially ecosystem-based adaptation, and including approaches that adhere to our definition of $\mathrm{NbS}$ for adaptation without explicitly referring to the term, are purported to often be more holistic and integrative than analogous infrastructural solutions (Woroniecki et al. 2019, Chausson, Turner et al., 2020). In a recent study of the first generation of NDCs to the UNFCCC, Global South countries were found to disproportionately include NbS as part of adaptation plans compared to global average (Seddon et al., 2020a). Dependency on local ecosystems for basic needs and livelihood strategies and lack of finance for technological approaches influence these adaptation choices (Munang et al., 2014; Mercer, 2012, Doswald et al., 2014). Moreover, long traditions of working with nature, and the role of the Development and Conservation sectors in these countries may also help to explain their prominence (Seddon et al., 2020a; Smith et al., under peer review) $)^{1}$.

\footnotetext{
${ }^{1}$ As the Convention of Biological Diversity states: “EbA and Eco-DRR have gained traction because they provide multiple benefits for people, ecosystems and biodiversity, enable planning for CCA and DRR on longer time scales, are cost-effective compared to traditional engineered infrastructure, and emphasize community participation and the use of traditional and local knowledge systems. Due to their participatory nature and cross-sectoral approaches to adaptation and disaster risk reduction, EbA and Eco-DRR can achieve multiple
} 
Despite such apparent relevance, the role of $\mathrm{NbS}$ in the Global South is understudied compared to the Global North. Given the increasing evidence at the global level of the effectiveness of NbS to reduce vulnerability to climate impacts and deliver co-benefits (Osaka et al., 2021; Du et al. 2020) there is a paucity of research specifically focussed on the Global South. A recent systematic map of the evidence for NbS for addressing climate change impacts shows that only $15 \%$ of NbS studies stem from interventions in the Global South (Chausson, Turner et al, 2020). Addressing this imbalance is a priority research task, especially given the disproportionate vulnerability to climate change and related knowledge needs of the Global South (Chausson, Turner et al., 2020). Thus, understanding what works for reducing vulnerability in the global south is a priority knowledge concern (Chausson, Turner et al., 2020; Seddon et al., 2020b). More systematic analysis is required to understand if and how NbS are effective for addressing the vulnerability contexts of the most vulnerable groups.

To address this gap, here we present a systematic analysis of the evidence on effectiveness of NbS in the rural areas of the Global South (defined here as low and lower middle-income nations) to address climate change vulnerability. By moving away from a risk-hazard approach and acknowledging the diverse ways that vulnerability is co-produced in particular settings and for particular people, the analytical framework we use is relevant to addressing the vulnerabilities of marginalised rural communities (Thiault et al., 2018). We use a social-ecological systems framework centered on peopleat-risk and explore how people's vulnerability to climate-related hazards is affected by nature-based interventions across a wide range of peer-reviewed case studies. By using this approach, the study also addresses the general theoretical gap identified by Welden, Chausson et al. (2021) in terms of how NbS effectiveness is mediated by in-situ social and ecological factors, such as contextual institutions and social-ecological interactions (cf. Osaka et al., 2021; Coloff et al., 2021).

Making use of a dataset of peer-reviewed studies collected through a systematic screening and coding procedure (Chausson, Turner et al., 2020), here we present a framework of social-ecological vulnerability and use it to systematically analyse the ways NbS affect people's climate vulnerabilities.. We analyse 85 interventions across 66 separate studies in the rural Global South. Our aim is to understand how and in what ways NbS reduce people's vulnerabilities in the rural Global South. We first outline the contextual diversity of the dataset, including ecological elements such as hazard and ecosystem type, as well as social elements such as beneficiary groups and institutions. We then use

policy objectives, including local, regional and national strategies for climate change, disaster risk reduction, and sustainable development, among others." $\underline{\mathrm{CBD}, 2018}$ 
the social-ecological vulnerability framework to deductively analyse the outcomes of the interventions, conceptualising effectiveness in terms of reducing people's social or ecological vulnerability through the pathways of exposure, sensitivity, and adaptive capacity. Our framework acknowledges that a nature-based intervention can shape vulnerability both through its effects on ecological attributes but also through social attributes. We refer to these social and ecological means through which vulnerability is affected and reduced as pathways. Finally, we undertake an inductive analysis of mediating factors that appear to shape effectiveness.

Our research questions are:

1. In which ecological, geographical and social contexts are NbS represented across the rural Global South?

2. How effective were NbS in reducing people's vulnerability, and through which socialecological pathways?

3. Which factors are reported to mediate the effectiveness of NbS in reducing people's socialecological vulnerability?

\section{THEORY}

\subsection{Conceptual Framework}

\section{Climate Change Vulnerability}

The concept of vulnerability to climate change is a central part of climate research and action (IPCC AR5, 2014; Simpson et al., 2021). The IPCC conceptualises climate change vulnerability in terms of three components: exposure, sensitivity and adaptive capacity (see Box 1 for definitions). In order to reduce people's vulnerability, an adaptation action needs to reduce exposure and/or sensitivity, and/or increase people's adaptive capacity.

Researchers have examined how particular framings affect which adaptation actions are deemed appropriate (O Brien et al., 2007; Eriksen et al. 2021; Singh et al. 2021). Researchers have found that technological and hard-infrastructural focussed approaches to adaptation that have predominated todate and that this has been been driven in part by vulnerability frames that tend to sectorise vulnerability, and focus on the climate hazards themselves, rather than the contexts in which vulnerability is produced and experienced by people (ibid). Such contexts entail the various conditions 
and 'system states'; biophysical, ecological, political, social and so on, that interact in order to shape why some places and groups of people experience relatively vulnerability to climate change than others (Ribot, 2010; Schipper et al., 2016; Atteridge and Remling 2018).

Research has demonstrated how focus on vulnerability contexts better reflects how vulnerabilities are generated in people's lives across the rural Global South (O Brien et al., 2007; Ensor et al., 2019; Quealy and Yaters, 2021). Climate is very rarely the only kind of risk that people face, environmental or otherwise. Furthermore, climate hazards may be multiple and overlapping, such that focussing on vulnerability to one particular hazard-type does not properly capture how climate change affects people's lives, nor why and how people respond in particular ways through their adaptative strategies (Olsson et al., 2014; Pinho et al., 2014). In these ways, vulnerabilities to multiple and interacting climate hazards can be seen as dimensions of complex systems (ibid). With detailed contextual knowledge, and creative expressions of agency, people work on and in systems in order to shape the conditions of their lives and reduce these vulnerabilities (Jones et al., 2012; Krasny et al., 2014; Lavorel et al., 2020; Bhowmik et al. 2021).

\section{Socio-ecological vulnerability}

While the three components of vulnerability - exposure, sensitivity and adaptative capacity - as conceptualised by the IPCC provide a comprehensive definition, this definition does not explicitly demarcate ecological and social sub-components, nor make explicit how their interactions in a given context influence (or 'produce') vulnerabilities. Conceptualizing vulnerability without making explicit social and ecological dimensions may miss important pathways through which people are affected by climate impacts, and how they respond to the prospect of those impacts through adaptation, especially in the rural global south. These are important gaps especially in relation to $\mathrm{NbS}$, given that vulnerability is produced in the social-ecological interactions of climate hazards and the contexts in which they materialize (c.f. Schmit and Wandel, 2006; Seddon et al., 2020b). The assumption underlying the present study is that each of the three components of vulnerability can be usefully separated into their social and ecological dimensions in order to understand the role played by NbS in reducing people's vulnerabilities in a given context.

Recently, there has been a focus on understanding vulnerability in social-ecologically-explicit ways (Cinner et al., 2012; Thiault, et al., 2018; Depietri, 2020; Seddon et al., 2020b). Though such conceptualisations do not commonly directly address climate change - rather vulnerability to any kind 
of shocks and stresses - these frameworks help to contextualise vulnerability as the property of a social-ecological system (SES) -- involving social and ecological structures, functions and their dynamic interactions (Adger et al., 2009; Gallopin, 2006; Brink et al., 2016; Lavorel et al., 2020). SES scholarship has enabled understanding of these interactions, which are often a key means through which people secure resources, meet their livelihood strategies and alleviate risks (Fischer et al., 2015; Daw et al., 2016; Hoque et al., 2018).

By focusing on social-ecological interactions, this emerging SES approach provides a framework for understanding the interactions between climate hazards, the state of a given system, and the outcomes for people, and in turn how adaptation action may influence people's vulnerability. Building on previous studies, we use an SES approach to construct a social-ecological vulnerability framework that reveals the distinct pathways through which NbS shape vulnerability, to a degree that has thus far been missing beyond particular case studies. The advantage of an SES lens is that it makes explicit both the pathways through which NbS act in the system, as well as the contextual variables that shape vulnerability for particular people and places. Outlining distinct social and ecological pathways to vulnerability reduction is a key conceptual advance on previous analyses and addresses some key issues of relevance to GS contexts; namely the integrated character of vulnerability and the need to consider all aspects of $\mathrm{NbS}$ and their effects on people.

\section{Nature-based Solutions and vulnerability reduction}

Here we conceptualise vulnerability as a property of social-ecological systems to make explicit the contributions of NbS for vulnerability reduction. Importantly we go beyond a sole focus on ecosystem services, which has predominated as an approach to study the outcomes of NbS (Cf. Brink et al., 2016). This provides the basis for understanding how an adaptation intervention; ecosystem-based or otherwise, may alter a given SES in either or both of its social and ecological dimensions and in so doing reduce people's vulnerability to climate change.

Our conceptualisation builds on previous studies (Cinner et al., 2012; Depietri, 2020; Thiault et al., 2018; Seddon et al., 2020b) by making explicit the 1) the ways people are situated in and depend upon SES, and likewise shape changes to the system through their practices and institutions; 2) the ways that people's vulnerability to climate change depends significantly on distinct components of social and ecological exposure, sensitivity and adaptive capacity 3 ) the roles of NbS in reducing people's vulnerability of the SES to climate change via the aforementioned dimensions, which are termed 
vulnerability-reduction pathways; and, 4) the role played by institutions and other mediating factors in shaping even 'nature-based' adaptation actions and their impacts.

Conceptualising vulnerability in terms of the contextual conditions into which a hazard materializes allows understanding how an NbS may intervene in the system to influence either or both social and ecological dimensions of people's vulnerability. An important distinction here is that this approach makes clear how the process of conserving, restoring and management of SES central to the concept of NbS (e.g. Nesshöver et al., 2017; Seddon et al., 2020a) can have additional effects on vulnerability that go beyond changes to flows of ecosystem services. Our conceptualization therefore contrasts with previous conceptualizations of social-ecological vulnerability (see Thiault et al. 2018, Depietri, 2020, Seddon et al., 2020b), which focussed on "social" vulnerability through the lens of a stressor's impact on ecological vulnerability. This conceptual shift/expansion of social-ecological vulnerability was necessary to make visible non-ecological pathways through which $\mathrm{NbS}$, understood here as adaptation interventions, can shape people's vulnerabilities, directly or indirectly. People's vulnerability can indeed be shaped by a system's ecological attributes as recognised in these previous studies. In this study we use the term 'ecological pathways' to denote the ways that NbS act upon the vulnerability a system's ecological attributes (systemic ecological elements which people depend on or gain value from). We add to this a new focus on non-ecological pathways, which we refer to as 'social' pathways. Such social pathways denote the vulnerability of social attributes (any asset or resource not connected to an ecosystem, including people themselves). These parallel social pathways closely fit the IPCC's definitions of vulnerability components (Box 1), even whilst these are relegated in these previous studies as indirect outcomes of ecological pathways. This allows us to more-fully capture the diverse pathways through which people's vulnerability is acted upon by NbS. 


\section{Ecological pothwoys}

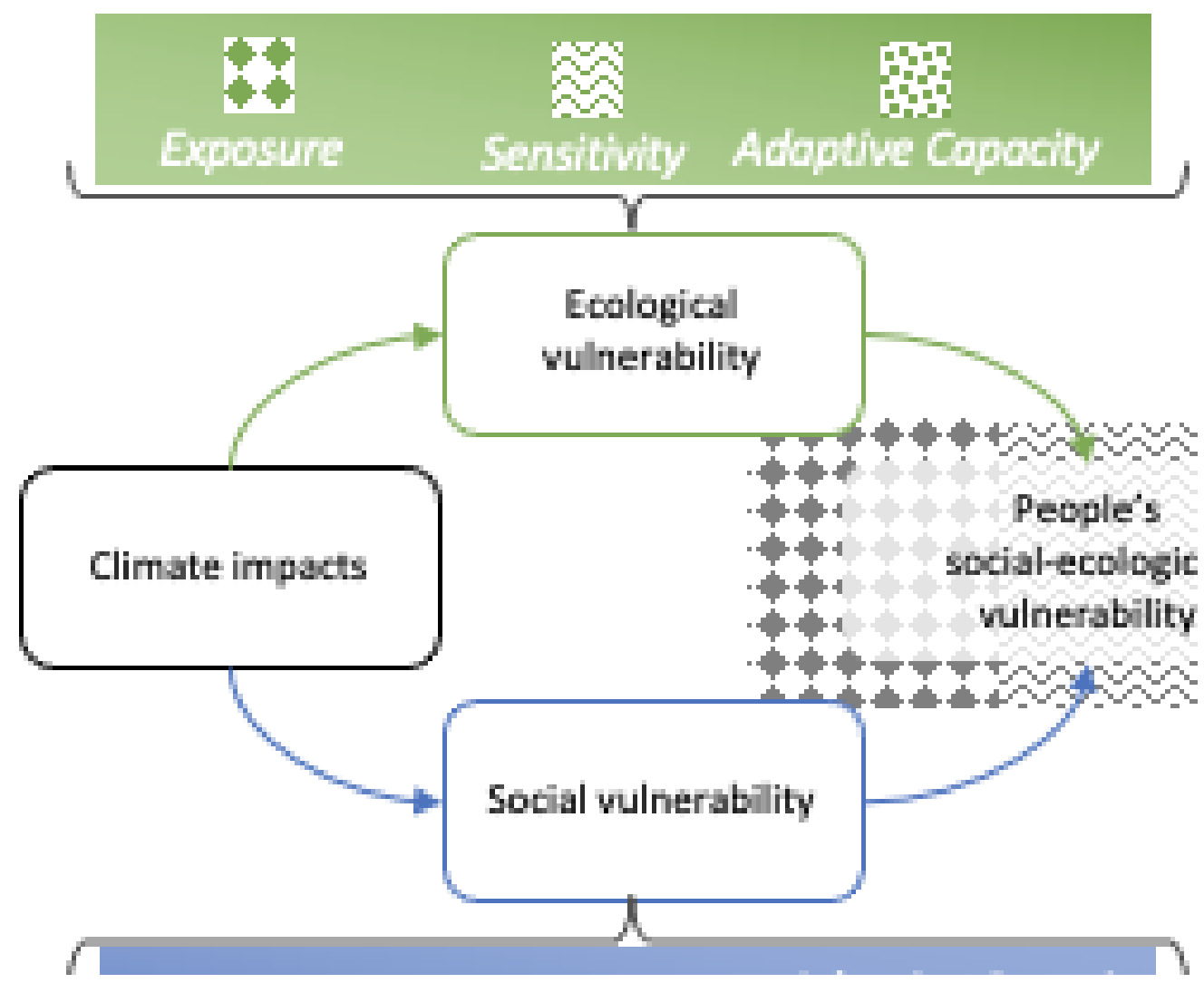

Figure 1 - Conceptual Framework of the social-ecological vulnerability framework that NbS act upon. The social and ecologically- differentiated framework shows six different pathways that produce people's socialecological vulnerability. NbS act upon this people-centred system through corresponding vulnerability reduction pathways', and their outcomes work along those six pathways.

This focus on the contextual conditions into which a hazard arrives also makes explicit how NbS is a function of the context in which it sits (Figure 2). In other words, it is embedded and shaped by the same social-ecological context that drives vulnerability. An NbS is the product of social-ecological processes and interactions, including institutions. In turn, a NbS has social and ecological outcomes, including those that affect vulnerability. Due to the ways that a NbS is part of and also produced by a given social ecological system, the outcomes of a NbS also inevitably feed back on the contextual conditions that produce it. 


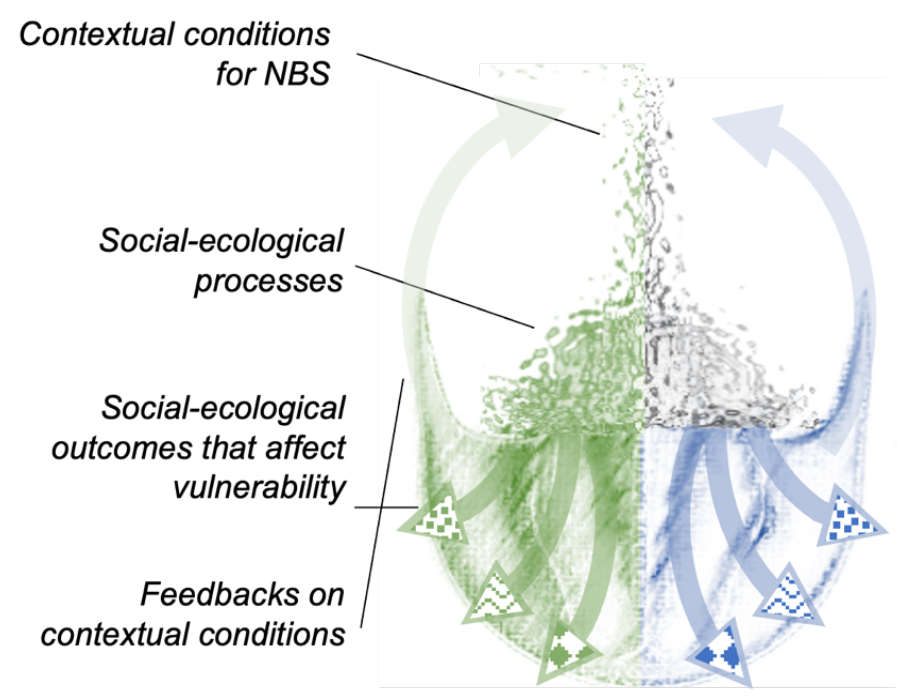

Figure 2 - Conceptualisation of NBS and its generation, interaction and outcomes within a social-ecological system.. The green and blue colors represent the ecological and ecological dimensions of the NBS respectively. The Figure 2 shows the 'melting pot' of NbS, which, like the vulnerability that it acts upon, is also necessarily a function of a given social-ecological system. $\mathrm{NbS}$ is a function of the context as well as a product of socialecological processes and interactions. Thus NbS outcomes have a feedback loop.

\section{Institutions}

Previous work on SES has focused on the importance of institutions in governing social-ecological relations (Polishchuk and Rauschmayer et al., 2012; Daw et al., 2016; Partelow and Winkler, 2016). Since our conceptual framework sees vulnerability as both related to a climate hazard as well as the conditions of the system itself (see Figure 1), understanding such conditions is crucial to our understanding of vulnerability reduction pathways (Woroniecki et al., 2019). These contextual conditions are to a large extent shaped by institutions. Therefore, we extend the SES focus on institutions by looking at their influence on and interaction with NbS intervention.

Institutions are generally referred to as mechanisms that shape recurring and continuous behaviour in a social setting (Huntington, 1996). Such mechanisms cannot be easily defined as institutions can range from political organisations, legal rules, and economic structures to cultural norms, religious rules, and societal systems. Institutions can be both formal, where mechanisms are officially established, or informal, which are socially shared (Mahoney \& Thelen, 2009). To account for the role of institutions in shaping vulnerability, our framework builds on a wide range of institutions including formal and informal mechanisms (cf. North, 1991; Ostrom 2006; Young, 2011; Partelow and Winkler 2016).

\section{Method}




\subsection{Data Collection}

We draw on the dataset from the global systematic map of NbS for adaptation compiled by Chausson, Turner et al. (2020), updating it to include studies through April 2020 in Low- and Lower-MiddleIncome Countries (World Bank, 2020). In total, we captured 68 studies, published in academic journal articles and recorded on Web of Science, comprising 87 interventions in total (See Supplementary Material; Study References). The data collection methodology, including the steps of scoping, searching, selection can be found in Chausson, Turner et al. (2020). To prepare the dataset for systematic review, we critically appraised each study, excluding cases where no human subject (social group, community or otherwise) was explicitly mentioned in the relevant study. We also excluded studies that did not specify a scientific methodology for compiling and assessing their results. Two cases were removed from the dataset for not fulfilling these criteria, resulting in a final dataset of 85 interventions.

\subsection{Data Coding}

The coding strategy is based on our conceptual framework on the contextual conditions of NbS, the pathways of social-ecological vulnerability, mediating factors and institutions. These aspects of the framework and their definitions guided the coding protocol, which was applied to specific intervention-cases, which could be multiple for included studies (see Supplementary Material; Analysis Table). The dataset was thus coded at the intervention level, which could target multiple climate impacts.

\section{Context variables}

To describe the context, we coded this dataset according to country of study focus, income level of country, ecosystem type, climate change impact type and type of intervention (c.f Chausson, Turner et al. 2020 for the methodology). We also made a categorisation of beneficiary groups through an inductive approach using the available information. Most commonly such groups were classed by livelihood group, which is a commonly used variable in frameworks of social-ecological interactions in SES research in the global south (e.g. Daw et al., 2016), along with institutions.

\section{Institutions}


Each article was reviewed to examine how institutions were developed or built upon to implement $\mathrm{NbS}$ or how they altered the contextual conditions in which the NbS occurred. The reviewers firstly identified any institutions as per the definition in 2.1.4. When more than one kind of institution was identified in the study, all were coded for, except where these were irrelevant to the conduct or context of the NbS. We categorised institutions as historical, contemporary or intrinsic to account for the temporal aspects of institutional effects and the interactions between the conduct and context of an NbS (cf. Woroniecki, 2019). Historical institutions are those that altered the system's contextual conditions in the past, for example by improving/exacerbating climate change impacts or by affecting components of human vulnerability. Contemporary institutions are mechanisms active when a NbS is implemented. Although they do not constitute an integral part of the intervention, they play a role in shaping the contextual conditions or by directly interacting with the pathways of vulnerability reduction. Intrinsic institutions are coded as integral to the intervention itself, part of its constitutive character and conduct, affecting how the NbS manifests in a particular SES. The institutional analysis is not exhaustive and limited by the extent to which study authors recognised the institutions. It provides a mid-range theory that allows further exploration of the influence of institutions on the NbS.

\section{Vulnerability Reduction Pathways}

To extend the understanding of NbS and vulnerability in a social-ecological context, our socialecological vulnerability framework conceptualises if and how nature-based interventions identified in the dataset intervene in a particular system to social-ecological vulnerability. We first categorised if the intervention made a positive, negative, mixed or unclear effect on the vulnerability of the groups in question depending upon the outcome statements identified in the case studies (see Chausson, Turner et al., 2020 for details of the methodology). Impacts were positive when one dimension was reduced and there was no indication of another dimension worsening. Impacts were mixed when one dimension was reduced and another was worsened, and such mixed impacts could be also categorised in case where some groups benefited whilst for others the situation worsened. Negative impacts were recorded one dimension was worsened and there was no indication of another dimension being reduced.

This framework introduces a social-ecological dimension to the IPCC's most recent definition of vulnerability, thus becoming the 'propensity of a given system to be adversely affected by climate change-related hazards as a result of changes to valued ecological and social functioning and 
processes (c.f. IPCC, 2014). We analyse how the NbS interventions alter this propensity by acting upon these functions and processes (which we call attributes) through the 6 possible distinct pathways of social and ecological exposure, sensitivity and/or adaptive capacity of the system (Figure 1). To do this we coded the identified papers for changes to people's vulnerability attributed to the intervention, and then disaggregated vulnerability effects according to social and ecological pathways, following the definitions given in Box 1. Our framework determines that whether social (e.g. livestock, or built infrastructure) or ecological (e.g. native mangroves), these attributes of SES are vulnerable to climate change in terms of their exposure, sensitivity and adaptive capacity (see box 1 for definitions used in coding). We thus code for up to six potential pathways through which a given NbS can influence the vulnerability of a given system. These were non-exclusive categories; an intervention could reduce vulnerability of up to six pathways.

The social and ecological pathways to vulnerability reduction are equal and distinct in terms of their placement within the vulnerability reduction framework. In our analysis the social and ecological pathways do not precede from one another, or likewise proceed from one another. Where a pathway transitions to another pathway (such as where an intervention reduces soil erosion to protect mangroves from sea level rise, which then protect social attributes such as a village from climate impacts), we only included the first pathway of vulnerability reduction, in order to avoid double counting. Thus, if an intervention is coded for multiple vulnerability reduction pathways, these are to be understood as distinct contributions to reducing people's vulnerability. We avoid any speculation about indirect vulnerability reduction effects not attributed directly in the particular study.

As previously justified, we do not analyse vulnerability solely in relation to specific climate change hazards but rather analyse the effects of the NbS on vulnerability to climate-related stressors more broadly. Moving away from the hazard-risk approach considers how vulnerability is a systemic property, meaning that our framework presupposes vulnerability is a co-production between a particular place, its people, and their interaction with environmental stressors, including climate hazards. Furthermore, given that the interventions were not necessarily implemented with the intent to address climate hazards, this allows for a more precise analysis of what occurred in the respective interventions, analysing not for individual climate change impacts but for the integrated outcomes of the intervention (whether positive, mixed or negative).

Box 1 Definitions of the 6 Vulnerability Reduction Pathways

\section{Vulnerability Reduction Definition \\ Pathways}




\begin{tabular}{ll}
\hline Ecosystem exposure & Extent to which species or ecosystems, environmental functions, \\
& services, of value to people in a given system are subject to pressures \\
(floods, droughts, landslides, fires, etc.) through their presence in a \\
particular location. It is determined by the intensity, duration and \\
frequency of events, geomorphology and the extent of use and \\
management of natural resources by human societies. \\
(Seddon et al., 2020b) \\
Degree to which ecosystem structure and function alters as a result of \\
perturbations. \\
(Seddon et al., 2020b) \\
Ecosystem sensitivity \\
capacity \\
processes (species, ecosystems, landscapes) to adjust to potential \\
damage, to take advantage of opportunities, or to respond to \\
consequences. (IPCC, 2014) \\
Presence of people, livelihoods, household assets, resources, \\
infrastructure, economic, community or cultural assets in places and \\
settings that could be adversely affected. (IPCC, 2014) \\
Degree to which these people, livelihoods, household assets, resources, \\
infrastructure, economic, community or cultural assets are affected, \\
either adversely or beneficially, by climate variability or change. The \\
effect may be direct (e.g., a change in crop yield in response to a \\
change in the mean, range or variability of temperature) or indirect \\
(e.g., damages caused by an increase in the frequency of coastal \\
flooding due to sea-level rise). (IPCC, 2014) \\
The ability of the units that provide valued functions and processes \\
(households, communities, social and cultural institutions) to adjust to \\
potential damage, to take advantage of opportunities, or to respond to \\
consequences (of climate change). (IPCC, 2014) \\
nocial adaptive \\
n.b. in coding we differentiated social sensitivity and adaptive capacity \\
according to a temporal scheme. Sensitivity relates to present effects \\
(i.e. those that were shown to affect the sensitivity of the system now) \\
whilst adaptive capacity builds capacity to response to potential \\
changes.
\end{tabular}

For the analysis of vulnerability reduction pathways, a necessary criterion is that there is a visible and direct contribution of NbS to people's vulnerability. Any vulnerability reductions that do not show a clear link to reducing people's vulnerability to climate change were removed at the quality appraisal stage (see below). To code for these six pathways of vulnerability reduction in the dataset we are limited in our view by the case studies themselves. This introduces some limitations which are outlined in the discussion.

\section{Mediating Factors}

We also conducted an inductive analysis of mediating factors, i.e. elements stated to modify the outcome of the intervention. This entailed identifying any passages of the studies that appeared to show conditioning effects and variables on the outcome of the intervention. We then applied an 
inductive approach to abstract these variables from the respective variables and group them into more general categories.

We extracted coding extracts highlighting mediating factors, i.e. elements stated to modify the outcome of the intervention. These extracts were then progressively abstracted through an inductive process producing emergent codes in the form of mediating factor categories and sub-categories. Finally, mediating factors were coded with respect to five categories (social, ecological, technical, economic, political and combination). To ensure coding consistency, data extracts and coding decisions were all validated by the second reviewer, who checked emergent codes were a good fit for emerging definitions, by cross-checking a text-based justification column. We also paid special attention together to uncertainties and discussed these carefully. The ways that institutional factors mediated vulnerability reduction is included under political mediating factors.

\subsection{Verification}

To ensure further consistency and coding accuracy for interventions/studies coded by a single reviewer, all coding decisions were verified by a second reviewer checking coding extracts with justifications for coding decisions in accordance with the definitions of the six pathways. Discrepancies or uncertainties in regarding the coding and definitions were resolved through regular meetings between the reviewers. To improve inter-coder reliability, 48 intervention-cases (56\% of interventioncases) were coded by both reviewers (Author's Initials withheld for review*) independently, with any identified discrepancies resolved before single reviewer coding. This improved a shared understanding of the various ways in which vulnerability pathways could be expressed in the dataset.

\subsection{Data Analysis}

The coding and cateogorisations were collated in MS Excel, with both quantiative (i.e. binary and numerical) and qualitative (i.e. text-based) data extraction columns to enable descriptive statistical analysis and in-depth qualitative analysis to explore patterns, elucidate paradigmatic examples and explore relationships between different variables. The inductive coding categories (e.g. mediating factors) were also produced in this table. Any inductive codes and emerging causal inferences were cross-checked and discussed at length by study authors to improve reliability. The evidence base was characterized through descriptive statistics, reporting the number of studies with respect to contextual parameters (e.g. Geography, climate impacts, ecosystem types) (section 3.1). We describe 
the evidence base in terms of absolute numbers and percentages of intervention-cases within framework categories (e.g....)

\section{RESULTS}

\subsection{Contextual diversity}

$R Q:$ In which ecological, geographical and social contexts are NbS represented across the rural Global South?

Our dataset is highly heterogeneous in relation to geography, climate impacts, ecosystem type, intervention type, and institutional diversity. In other words, very few of the configurations of country, climate impact, ecosystem type, intervention type and institutional set-up occur more than once.

\section{Geographic distribution of studies}

Our dataset represents 85 interventions from 66 studies across 28 low-income and lower-middleincome countries (Fig 3). These figures show how a few countries are overrepresented in the dataset, notably Kenya, and Ethiopia (14 and 11 interventions, respectively), whilst most account for only one, two or three interventions. The top 5 countries with the greatest number of interventions reported countries (Kenya, Ethiopia, Nepal (6 interventions, Indonesia, 5 interventions, and Philippines 5 interventions) make up $51 \%$ of the dataset.

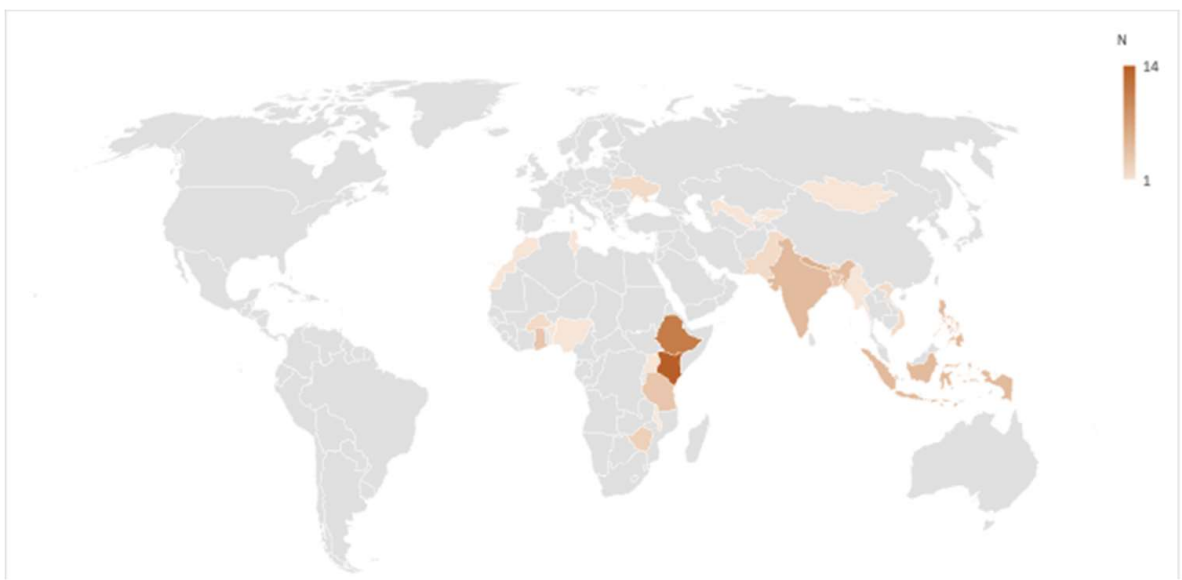

Figure 3 shows the geographical distribution of countries represented in the dataset. 
The African and Asian continents were well represented, while no countries from Latin America or the Caribbean were included. Most countries in this region are upper-middle, or high income (World Bank, 2020), and for those that are lower income incl. Bolivia, Honduras and Nicaragua, no studies were included. However, there are marked regional disparities: Whilst East Africa is well represented many African countries did not have a single study. Likewise, in Asia, South Asia was often counted, with Nepal, India, Bangladesh and Pakistan all with relatively higher representation, whilst some countries in South-East and Central Asia were not present, or only lightly. Europe was covered by a single intervention in Ukraine. Only one Small Island Development State (Vanuatu) was recorded in the set of cases from the Global South (despite other SIDS being captured in the Systematic Map, these were not low or lower-middle-income countries).

\section{Climate Impacts}

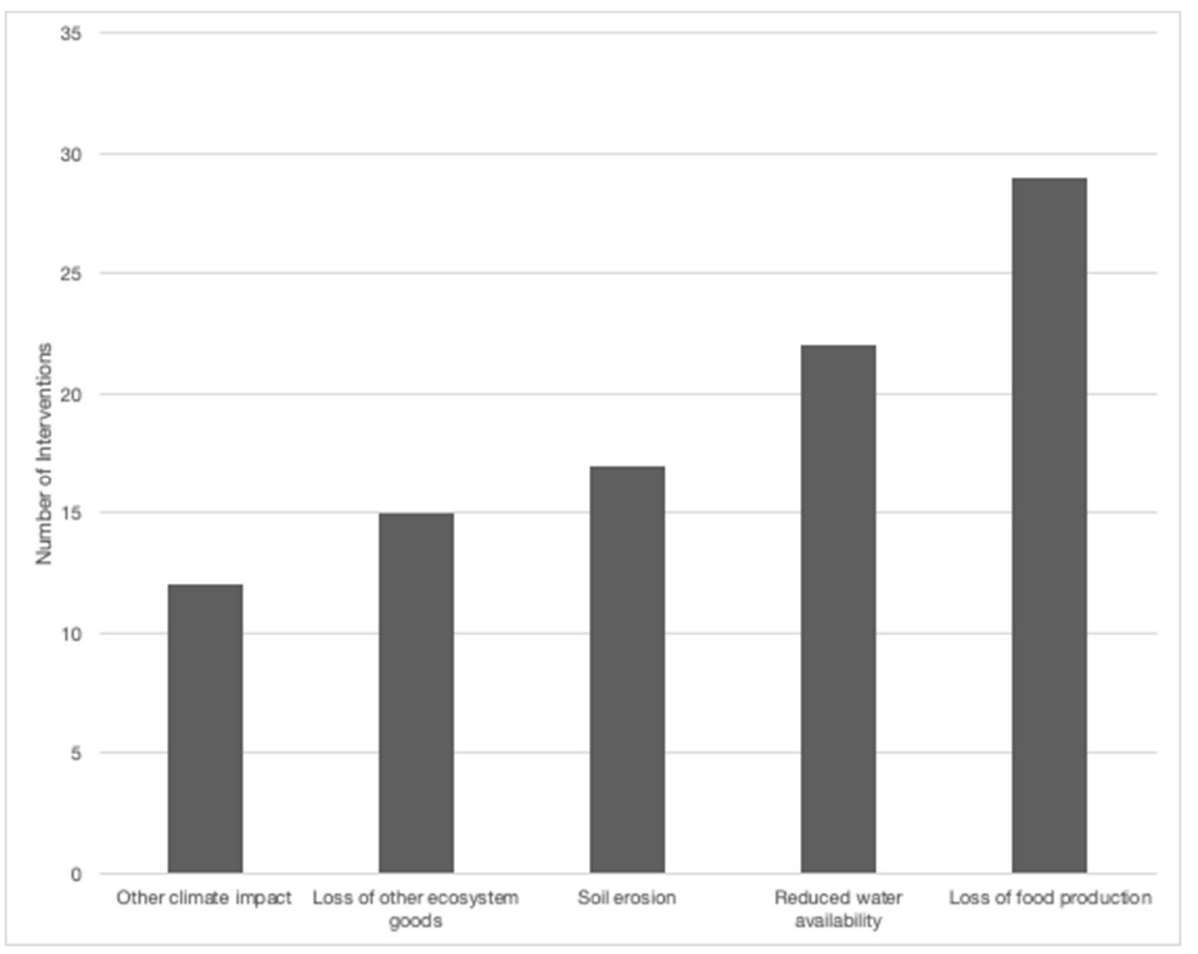

Figure 4 shows the 5 most commonly occurring climate impacts and the number of separate interventions in which they occurred (Y axis).

18 climate impact types were identified, with most interventions addressing one impact, up to a maximum of 9 (mean $=1.6)$. The representation of climate impacts across the dataset is skewed, with 11 climate impacts represented in 5 or more cases (Fig 4), and 4 climate impacts represented in 10 or more (the category 'other climate' impact refers to all other kinds of impact that were not represented 
in one of the coded categories). The most represented climate impact type was loss of food production (29 occurrences), whilst reduced water availability, soil erosion, loss of other ecosystem goods, other climate impact and drought were the other most commonly represented impact types.

\section{Ecosystem Type}

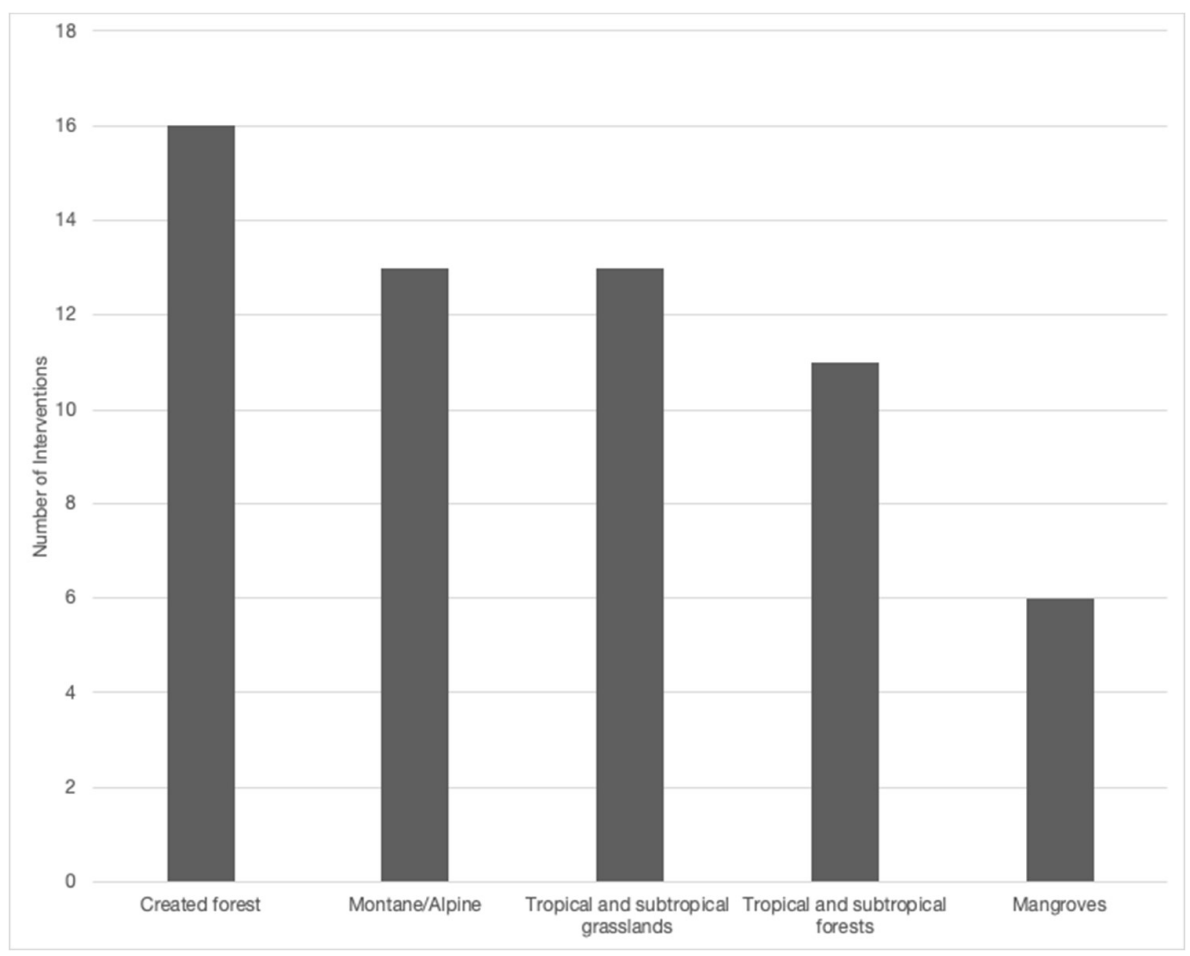

Figure 5 shows the 5 most commonly occurring ecosystem types and the number of separate interventions in which they occurred ( $Y$ axis).

We found interventions across 22 ecosystem categories (including combinations of different types addressed in a single intervention). Most intervention cases (68\%) were in created Forest (16), followed by Montane (13), Tropical and subtropical grasslands (13), Tropical and subtropical forests (10), and Mangroves (6) (Fig 5). The strong presence of tropical grasslands, forests and mangroves in the dataset coincides with the case representation in the dataset, which mostly fall in tropical or subtropical regions.

Intervention Type 
Most interventions $(35,41 \%)$ involved a combination of actions in natural or semi-natural ecosystems, followed by interventions in novel ecosystems $(21,25 \%)^{2}$. Few interventions involved protection (11), management (6), restoration (6), or the use of a mix of novel and non-novel ecosystems (4)

\section{Institutions}

Whilst these broad intervention types reveal broader patterns of data, an analysis of the institutions involved shows the diversity in the social contexts in which ecosystem-based adaptation actions are undertaken. Identified historical and contemporary institutions form the institutional context of the interventions and therefore play a crucial role in understanding the pathways of vulnerability reduction. Intrinsic institutions were identified in $52 \%$ of cases ( 44 interventions, historical institutions in $49 \%$ of cases ( 42 interventions) and contemporary institutions in $32 \%$ of cases ( 27 interventions).

\section{Historical institutions}

Where present/reported, historical institutions most often mediated the vulnerability reduction efforts for different groups by shaping the social-ecological interactions of the given context in which $\mathrm{NbS}$ intervene. For example, in a case involving exclosures to foster grassland regeneration, historical conflict management structures continued to favour sedentary communities over nomadic groups, marginalizing the nomadic community and increasing their vulnerability to CCls (Ahmad et al., 2012). Their marginalisation has led to more intensive grazing on limited available areas. This case illustrates how historical institutions shape the context in which the NbS is set, which consequently shapes/influences intervention design in relation to the exclosures and regulating access.

\section{Contemporary institutions}

Contemporary institutions (i.e. those that exist in parallel to the intervention) also shape the intervention context. For example, in a case involving assisted rehabilitation (restoration) of a seafront area in the Philippines, formal institutions (land tenure and fish pond licenses regulating access and ownership) were critical to the intervention's design, and implementation (ref study). The existing institution of the licences strongly determined the rehabilitation process (Duncan et al., 2016).

\section{Contextual institutional change}

\footnotetext{
${ }^{2}$ N.b. 'novel ecosystems does not include interventions occurring on the agricultural matrix (e.g. agroforestry) since these were excluded from the dataset (see Chausson, Turner et al. (2020) for exclusion criteria), but could include interventions that harness surrounding ecosystems (through protection, restoration, or other forms of management) to reduce vulnerability of agricultural systems to climate change (such as vegetation bunds or wind breaks).
} 
Cases with both historical and contemporary institutions often show contextual institutional change, mostly related to changes in ownership institutions. For example, Wairore et al. (2016) highlight how communities in West Pokot County, Kenya shifted from nomadic traditional grazing and rotating systems to sedentary approaches when colonialists implemented sub-national borders restrictions, dividing land previously customarily shared by all pastoralists amongst colonial landowners. These restrictions impeded migratory patterns, forcing communities into sedentary livelihoods. This shift in livestock grazing induced by institutional change has been the main driver of land degradation in the area. The institutional change also reiterated the need for formalising land ownership systems based on customary traditions, which became part of the intrinsic institutions of the intervention that included new agreements on land ownership and management, as well as the implementation and management of exclosures.

\section{Beneficiaries}

We identified a wide range of intervention beneficiaries across the studies. Most were rural communities whose livelihoods are directly dependent on and shaped by their local ecosystem. The most common livelihood identified was arable or mixed sedentary farming, often small-scale, with interventions identified in riparian, savannah, montane or forest ecosystems. Most target groups also held livestock, relying on agro-pastoralist systems. Nomadic pastoralists were also represented in the studies. These nomadic communities were, however, rarely studied on their own and were mostly addressed in combination with the sedentary communities. Finally, the last category of subjects that could be identified was that of coastal or river communities whose main livelihood was fishing.

\subsection{Vulnerability reduction outcomes}

RQ: How effective were NbS in reducing people's vulnerability, and through which social-ecological pathways? 


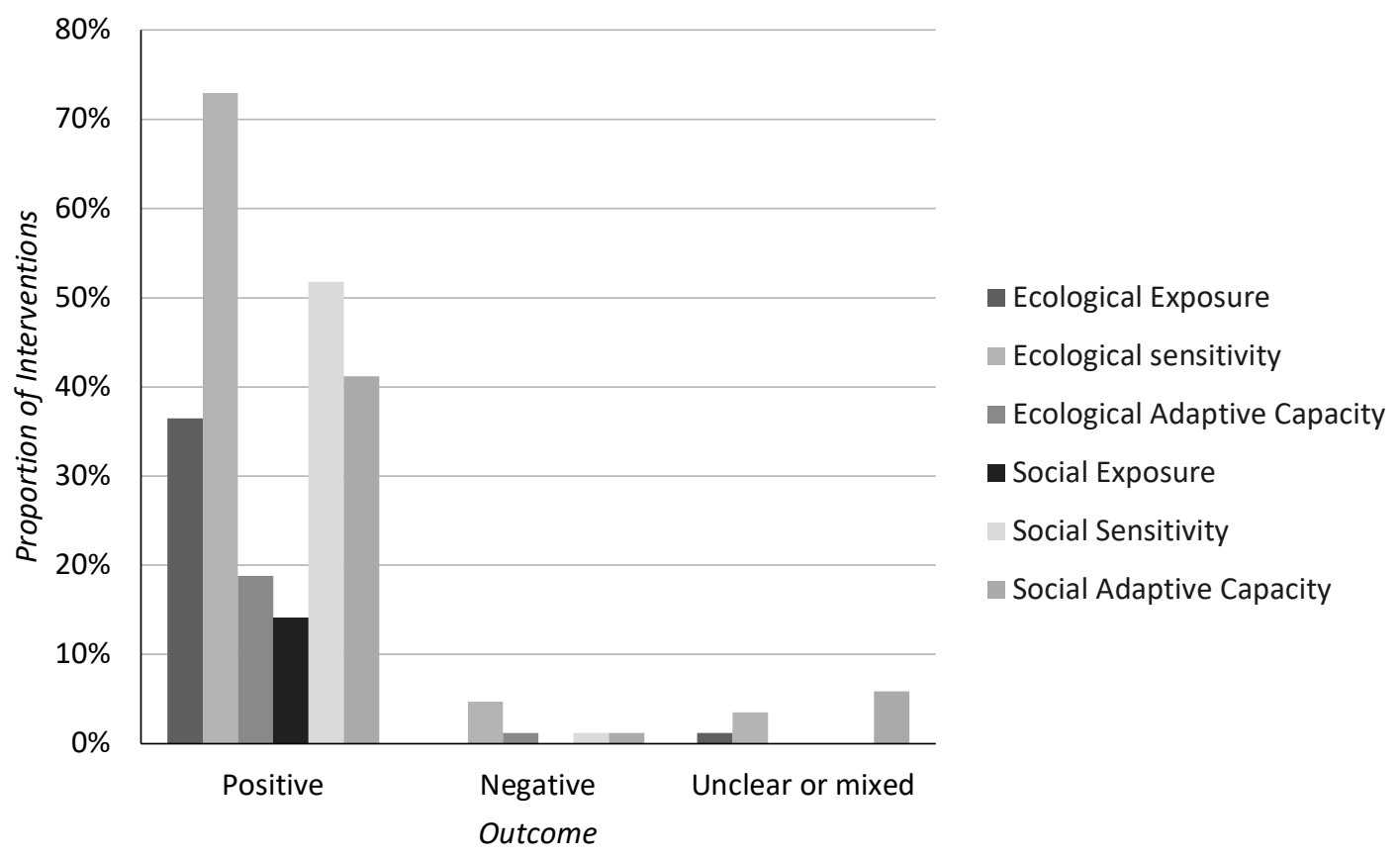

Figure 6 - Proportion of interventions displaying the 3 kinds of outcomes across the 6 vulnerabilityreduction pathways.

Figure 6 show the proportions of positive, negative and unclear or mixed outcomes of NbS interventions in reducing vulnerability. Most of reviewed interventions (95\%) reported positive outcomes in distinct vulnerability pathways. These are discussed in detail in section 3.3."

We found a 9 instances of unclear or mixed outcomes in distinct vulnerability pathways, with mixed cases often illustrating the importance of disaggregating intervention outcomes by social groups. For example, in the case of [19], the outcomes of the implemented exclosures in a watershed in Ethiopia differed between social groups. Poorer, marginalized farmers with little or no land, relying heavily on communal grazing areas, were now excluded from using the land, forcing them to reduce livestock ownership and turn to other livelihoods. In contrast, richer, land-owning farmers perceived exclosures as positive as the soil in the area regenerated and provided fodder.

In 7 instances across 5 interventions interventions negatively shaped distinct vulnerability pathways (two interventions reported two distinct negative outcomes each). For example, in an intervention funded by a Norwegian forestry company, in Dokolo district, Uganda, forest protection and afforestation for carbon offsetting reduced the area for potential cultivation, resulting in intensified agriculture and further degradation of available land. Ultimately, this led to loss of soil fertility and 
food production (Edstedt \& Carton, 2018). This exacerbated the area's ecological sensitivity, while water-demanding Eucalyptus trees depleted water resources in proximity to the village, forcing local people to travel further for freshwater. Here, forest protection also reduced firewood availability, making the community more exposed to price fluctuations of wood on the market while removing a stream of local income, ultimately increasing social sensitivity. Due to its poor design, the intervention yielded no positive outcomes for the community.

\subsubsection{Pathways of vulnerability reduction}

The most common pathway for vulnerability reduction was through reducing ecosystem sensitivity 62 interventions, 73\%) (Figure 6). Interestingly, the next two highest categories were social sensitivity $(44,52 \%)$ and social adaptive capacity $(35,31 \%)$, showing how interventions often shape a system's social attributes. Ecological exposure was the next most represented pathway (31,36\%), whereby the intervention reduces the exposure of the system's ecological attributes to a hazard. Ecological adaptive capacity and social exposures were the least represented pathways of vulnerability reduction $(16,19 \%$ and $12,14 \%$ cases, respectively). Importantly, nature-based interventions influenced socialecological vulnerability through distinct ecological and social pathways.

\section{Ecological Pathways}

In most cases (88\%), NbS influenced vulnerability through the ecological components of the socialecological system. As these systems are dependent on ecological attributes, this leads to changes in people's vulnerability.

\section{Ecological exposure}

Interventions addressed ecological exposure in different ways, but mostly by establishing natural barriers shielding the ecological attribute to the climate hazard. For example, in Kutubdia Island, Bangladesh, the creation of new oyster reefs on a tidal mud threatened by coastal erosion acted as a wave break, significantly reducing coastal hydraulic load, and ultimately exposure to coastal erosion (Chowdhury et al., 2019). This facilitated habitat restoration, boosting fish population, and in turn food production and income for the local population, reducing their vulnerability.

\section{Ecological sensitivity}

Most of the intervention cases indicated reduced ecological sensitivity, whereby regulating and supporting ecosystem services were improved or restored, consequently increasing the propensity for 
damage of ecological attributes to stressors. A good example is highlighted by Mekuria et al. (2015) for an intervention Northwestern Ethiopia involving exclosures to restore degraded land (and address soil degradation) in a montane ecosystem where people mostly depended on agriculture and livestock farming. The intervention involved seasonal protection of the lands from livestock grazing and harvesting (apart from grasses and roots), and spatial zoning of communal grazing lands.

First, the intervention shaped ecological sensitivity through land use and access restrictions, thereby reducing soil degradation and improving vegetation cover. This meant that the soil became less sensitive to climate- related-soil erosion as the vegetation cover reduced the impact of stressors like wind or water run-off. Second, the intervention rehabilitated water gullies, reducing soil erosion due from environmental stressors. As the soil improved, indigenous trees regenerated, vegetation cover improved, and fodder supply increased, benefiting livestock farmers dependent on soils for fodder and water.

\section{Ecological adaptive capacity}

In a subset of cases NbS improved ecological adaptative capacity (i.e. the capacity of the ecological attributes to adjust to a changing environment), often through the plantation of species tht are more resilient to extreme weather conditions. For example, in Koyra Upazila Bangladesh, a village affected by coastal erosion and saltwater intrusion, a mangrove forest comprised of salt tolerant species was planted to address these impacts (Imam et al., 2016). Mangrove trees improved the overall ability of the system to adjust to damage from saline intrusion.

\section{Social Pathways}

In a smaller but still sizeable proportion of cases (65\%), NbS influenced vulnerability through the social components of people's vulnerability.

\section{Social Exposure}

Several interventions used natural barriers to reduce the exposure of social attributes to climate hazards. For example, a rural community in Northern Ghana affected by fire and wind in a tropical grassland ecosystem established fire belts and planted small patches of tall vegetation around their village (Ngwese et al 2018). The fire belts (vegetation free corridors) prevented bushfires from reaching the village, whereas planted tall plants protected rooftops against heavy winds. Reduced exposure of material possessions and infrastructure consequently improved the vulnerability of the community. 


\section{Social sensitivity}

Multiple interventions reduced the sensitivity of a system's social attributes to climate hazards by means other than changes to the ecological attributes. In most of cases of reduced social sensitivity, interventions strengthened social cohesion or diversified livelihoods, minimising the impact of environmental stressors. For example, in the Panchase mountain region in Nepal, community-based forest management and landscape restoration were crucial, in multiple ways, to reduce villagers' sensitivity to environmental variability, and ensuing loss of ecosystem goods, food production, and water availability (Adhikari et al., 2018). The establishment of community forest managed increased social cohesion and inclusion through a social network, improving villagers' access to community support in times of difficulty. Furthermore, the community forest improved access to firewood and timber, and diversified livelihoods by generating employment and income from improved ecosystem goods. An education programme also improved capacities for ecosystem management and strengthened community-based institutions, such as mechanisms to manage forest services, platforms to discuss issues relating to their livelihoods, and participatory decision-making. Increased cohesion, strengthened institutions, and increased streams of income provided the community with the knowledge and material capacities to deal with climate change impacts locally.

\section{Social adaptive capacity}

Social adaptive capacity is often closely linked to social sensitivity. Where social adaptive capacity improved, communities were better able to cope with and adjust environmental change. For example, in the Lenche Dima watershed in Ethiopia in a montane ecosystem, a multi-faceted intervention established rangeland exclosures, plantation of multi-purpose trees, and management, education, institution-building and projects to foster community participation to address reduced water availability and loss of food production (Descheemaeker, 2010). Beyond directly addressing reduced water availability and food production, the intervention empowered the local community, which was crucial to improve adaptive capacity. Education in natural resource management, strengthened local institutions and generated new forms of income generation enabling people to adjust to change and take control of by identifying problems and potential solutions early, thereby reducing their vulnerability.

Box 2-Interventions associated with a particular vulnerability pathway, and a paradigmatic example of each pathway

\begin{tabular}{|l|l|l|l|}
\hline $\begin{array}{l}\text { Pathw } \\
\text { ay }\end{array}$ & $\begin{array}{l}\text { Intervention } \\
\text { numbers }\end{array}$ & Paradigmatic Example & Study Ref \\
\hline
\end{tabular}




\begin{tabular}{|c|c|c|c|}
\hline Eco Ex & $\begin{array}{l}2,3,4,8,14,18, \\
19,20,25,36,42, \\
44,46,47,48,49, \\
50,51,54,57,58, \\
60,66,68,75,76, \\
77,78,80,82,84, \\
85\end{array}$ & $\begin{array}{l}\text { Created oyster reefs reduced hydraulic load on the coast } \\
\text { by reducing exposure to large waves and coastal erosion. } \\
\text { The community's vulnerability improved as a result as } \\
\text { organism populations restored and the shoreline } \\
\text { remained intact, allowing the population to maintain their } \\
\text { livelihoods on the island rather than migrating to the } \\
\text { mainland. }\end{array}$ & $\begin{array}{l}\text { Chowdhury } \\
\text { et al., } 2019\end{array}$ \\
\hline Eco Sen & $\begin{array}{l}2,3,5,7,8-19,23- \\
30,31-38,43-45 \\
47,49,51,53-55 \\
57-62,63-79,81- \\
85\end{array}$ & $\begin{array}{l}\text { Exclosures and the limited harvesting of grasses and roots } \\
\text { restored land degradation, making the soil less sensitive } \\
\text { to climatic stressors. This improved the local people's } \\
\text { vulnerability as the increased vegetation provided cheap } \\
\text { fodder and restored water gullies which increased fresh } \\
\text { water supply. }\end{array}$ & Mekuria et \\
\hline Eco AC & $\begin{array}{l}11,15,16,30,31, \\
34,38,44,52,53, \\
59,68-71,76,81\end{array}$ & $\begin{array}{l}\text { The afforestation of salt-tolerant mangrove trees } \\
\text { improved the system's resilience to saline intrusion, } \\
\text { provided constant shadow for under-storey plants, and } \\
\text { could reduce waves in case of extreme weather, } \\
\text { increasing the system's ability to adjust to changing } \\
\text { environmental conditions. This improved the total } \\
\text { vulnerability as the community's fresh water was less } \\
\text { affected by saline intrusion and the resilient trees } \\
\text { provided a stable supply of firewood. }\end{array}$ & Imam et al., \\
\hline Soc Ex & $\begin{array}{l}4,7,8,20,31,42, \\
49,55,60,80,82, \\
84\end{array}$ & $\begin{array}{l}\text { The creation of natural barriers like fire belts and tall } \\
\text { vegetation reduced the exposure of the village to climate } \\
\text { hazards like fire and wind. By protecting the social } \\
\text { attributes, the intervention improved the vulnerability of } \\
\text { the community }\end{array}$ & $\begin{array}{l}\text { Ngwese et } \\
\text { al., } 2018\end{array}$ \\
\hline Soc Sen & $\begin{array}{l}1,3,4,6,8,9,13, \\
17,18,23,26,27, \\
29,31-33,38-41, \\
44,45,48,52-57, \\
59,60,62,64-66,\end{array}$ & $\begin{array}{l}\text { Landscape restoration and the implementation of a } \\
\text { community-managed forest diversified livelihoods } \\
\text { increased social cohesion, and provided natural and } \\
\text { human capital. This made the community less sensitive to }\end{array}$ & $\begin{array}{l}\text { Adhikari et } \\
\text { al., } 2018\end{array}$ \\
\hline
\end{tabular}




\begin{tabular}{|c|c|c|c|}
\hline & $\begin{array}{l}68-71,76,79,80 \\
82,83,85\end{array}$ & $\begin{array}{l}\text { the local effects of climate change and reduced their } \\
\text { vulnerability. }\end{array}$ & \\
\hline Soc AC & $\begin{array}{l}1,3,4,6,7,9,10, \\
12,13,17-19,23 \\
26,27,29,31-33 \\
39-43,45,48,52- \\
54,56,57,59,60 \\
62,65,68-71,76, \\
79,83\end{array}$ & $\begin{array}{l}\text { Rangeland exclosures and the plantation of multi-purpose } \\
\text { trees were used as the basis for institution-building and } \\
\text { education of the local community. This empowered the } \\
\text { local community to take charge of the changing } \\
\text { environment and gave the local the tools to adjust } \\
\text { accordingly. }\end{array}$ & $\begin{array}{l}\text { Descheema } \\
\text { eker, } 2010\end{array}$ \\
\hline
\end{tabular}

\subsubsection{Vulnerability reduction through multiple pathway interactions}

\section{Multiple ecological pathways}

Interventions often led to a vulnerability reduction through multiple ecological pathways simultaneously, either stemming from one or more intervention components addressing multiple pathways. For example, in an intervention involving the creation of mud piles/flood barriers to reduce exposure of agricultural land to flooding, the protection of native plants also provided a source of natural pesticides, reducing the sensitivity of crops to disease.

In a case involving exclosures in Ethiopia (ref.), multiple ecological pathways synergized (Crossland et al., 2018). Specifically, exclosures reduced land degradation and increased soil biodiversity, thereby reducing soil sensitivity, while improved soil conditions allowed for increased vegetation cover, providing shade and reduced runoff, reducing ecological exposure to heat and flooding. The overall improved conditions of soil biodiversity, landscape greenness and moisture levels improved the soil's adaptive capacity to environmental stressors.

\section{Multiple social pathways}

In most cases where vulnerability was shaped by social pathways, multiple pathways occurred. Social sensitivity was primarily addressed in combination with social exposure or adaptive capacity. For example, in an intervention involving the establishment of community-forests in Ethiopia (ref.), medicinal plants and enhancement of recreational and aesthetic values improved the local people's well-being and the communal participation and reduced their sensitivity to the effects of loss of income from droughts (Woldie \& Tadesse, 2019). The forest also diversified livelihoods, producing 
extra income streams to cope with loss of food production and of income as a result of droughts thereby increasing people's adaptive capacity.

\section{Multiple ecological and social pathways}

Most interventions reduced vulnerability through ecological and social pathways simultaneously, with pathways shaping vulnerability independently, or synergizing. An example of a case where social and ecological pathways acted in complement was an intervention of mangrove afforestation in the Mekong Delta in Vietnam, combining training for local people and employment projects (McElwee et al., 2017). The mangrove plantations functioned as shelter belts against waves and cyclones, thereby protecting the coastal system against waves and cyclones. The intervention also provided vocational training increasing local capacities to harness nature's contributions and develop coping strategies to environmental stress. In other words, this intervention reduced vulnerability through separate ecological and social pathways, reducing vulnerability in complement rather than through interaction and synergy.

In contrast, in an intervention involving exclosures to restore soil conditions in a tropical grassland ecosystem in Ethiopia, social and ecological pathways interacted and synergized (Crossland et al., 2018). A short period of protection reduced erosion, groundwater recharge, and increased grassland vegetation cover, which reduced the area's ecological sensitivity to climatic shocks. Simultaneously, exclosures brought farmers together through grassland restoration as a shared objective, reducing land use conflict through cohesion and cooperation, ultimately reduced farmers' social sensitivity to stressors. Reduced land-use conflicts, and improved cooperation diminished pressure on the lands leading to more sustainable ecosystem service management, facilitating ecological recovery. A positive, reinforcing feedback loop was evident, as ecological recovery reduced communal conflicts over now more abundant water, food and land for cultivation. This demonstrates how a single intervention component (exclosures) can reduce vulnerability through reinforcing social and ecological pathways.

\subsection{Mediating Factors}

RQ: Which factors are reported to mediate the effectiveness of NbS in reducing people's socialecological vulnerability? 


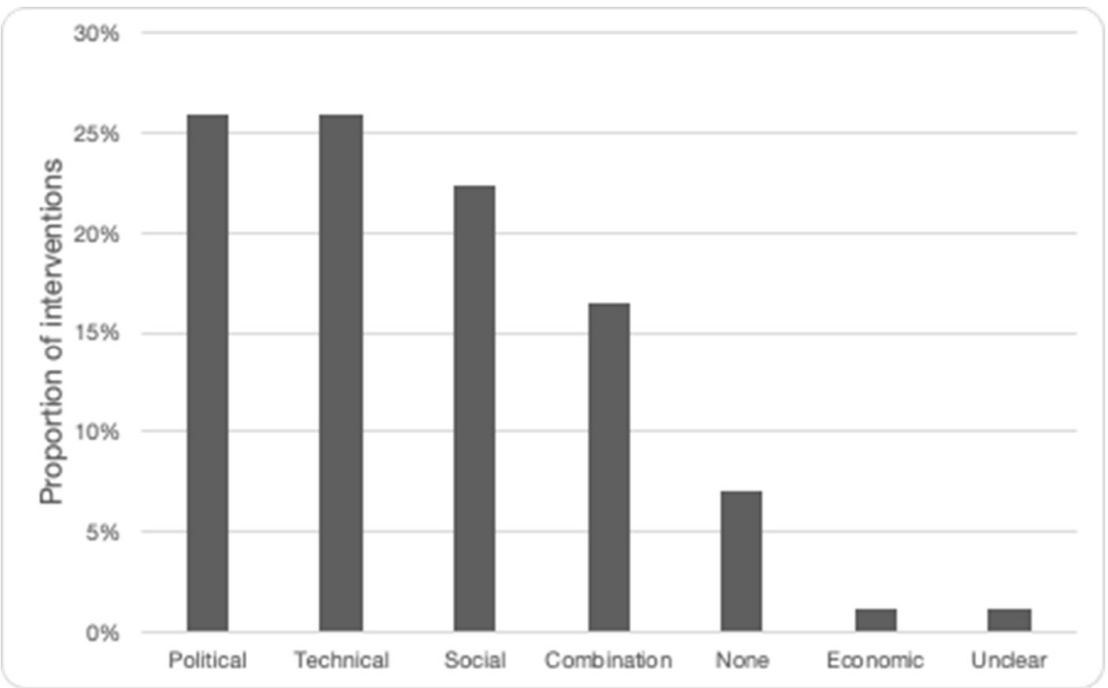

Figure 7 - Mediating factors Identified by type for the vulnerability reducing pathways, including combinations of types, where no mediating factor was identified, and where the mediating factor was unclear.

We found that $92 \%$ of the studied cases were associated by one or more mediating factors, which we found could be classed as technical (pertaining to the specifics of intervention design), social (pertaining to education and inclusion of knowledge, values, and community members), economic (pertaining to income, inequality and poverty levels), or political (related to historical, contextual, and intrinsic institutions and pertaining to issues of empowerment, ownership and access, conflict management). Sub-categories and paradigmatic examples of each are shown Box 3. As Figure 7 shows, the most common mediating factor types were political (including institutional factors), technical, and social, each mediating outcomes in various ways. Only $16 \%$ of cases mentioned more than one type of mediating factor.

Box 3 - Specific mediating factors for the effectiveness of NbS in reducing vulnerability, and subcategories, with a paradigmatic example to explain each one.

\begin{tabular}{|l|l|l|l|}
\hline $\begin{array}{l}\text { Mediating } \\
\text { Factor }\end{array}$ & $\begin{array}{l}\text { Sub- } \\
\text { category }\end{array}$ & Paradigmatic Example & Study Ref \\
\hline Technical, & $\begin{array}{l}\text { Specific } \\
\text { Design }\end{array}$ & $\begin{array}{l}\text { The specific length of the resting period to restore } \\
\text { rangelands in Tunisia was crucial to the level of } \\
\text { success. }\end{array}$ & $\begin{array}{l}\text { Belgacem et al., } \\
2018\end{array}$ \\
\hline
\end{tabular}




\begin{tabular}{|c|c|c|c|}
\hline Social, & Education & $\begin{array}{l}\text { The levels of education of the community prior to } \\
\text { the intervention proved to be a crucial mediating } \\
\text { factor for the level of uptake of the intervention } \\
\text { components. Formal education, for example, } \\
\text { increased the changes of accepting the new } \\
\text { system of land management. }\end{array}$ & Safari et al., 2019 \\
\hline & $\begin{array}{l}\text { Inclusion of } \\
\text { community }\end{array}$ & $\begin{array}{l}\text { The inclusion of the entire community supported } \\
\text { positive social outcomes as the empowered } \\
\text { community and social cohesion reduced social } \\
\text { sensitivity. The participated also allowed for } \\
\text { community-wide adoption of measures, which } \\
\text { mediated ecological outcomes. }\end{array}$ & $\begin{array}{l}\text { Descheemaeker } \\
\text { et al., } 2010\end{array}$ \\
\hline & $\begin{array}{l}\text { Inclusion of } \\
\text { local } \\
\text { knowledge }\end{array}$ & $\begin{array}{l}\text { Local knowledge on environmental conditions and } \\
\text { local community dynamics was recognised to be an } \\
\text { essential factor in avoiding inequity in the } \\
\text { community. }\end{array}$ & $\begin{array}{l}\text { Woldie } \\
\text { Tadesse, } 2019\end{array}$ \\
\hline & $\begin{array}{l}\text { Inclusion of } \\
\text { values }\end{array}$ & $\begin{array}{l}\text { Understanding the values that local people attach } \\
\text { to their local ecosystem proved crucial to } \\
\text { mangrove plantation in India. It was recognised to } \\
\text { ensure sustainability and appreciation by the } \\
\text { community. }\end{array}$ & $\begin{array}{l}\text { Badola \& Hussain, } \\
2005\end{array}$ \\
\hline \multirow[t]{2}{*}{ Economical } & $\begin{array}{l}\text { Income } \\
\text { creation }\end{array}$ & $\begin{array}{l}\text { Potential mediating factor is the generation of } \\
\text { income from the intervention. The community } \\
\text { forest in Myanmar ran on a voluntary basis, which } \\
\text { now hindered the outcomes as people were } \\
\text { unwilling to volunteer. }\end{array}$ & Lin et al., 2019 \\
\hline & $\begin{array}{l}\text { Poverty } \\
\text { levels }\end{array}$ & $\begin{array}{l}\text { The high levels of poverty in Myanmar constrained } \\
\text { the intervention because the poorest households } \\
\text { did not have the resources to spend time } \\
\text { volunteering in management and decision-making. } \\
\text { The outcomes of vulnerability reduction were, } \\
\text { therefore, not necessarily community-wide. }\end{array}$ & Lin et al., 2019 \\
\hline
\end{tabular}




\begin{tabular}{|l|l|l|l|}
\hline Political & Conflict \\
managemen & $\begin{array}{l}\text { Tribal conflict in Morocco was recognised as a } \\
\text { potential constraint of implementation, allowing } \\
\text { the intervention to use tribal organisations to } \\
\text { increase legitimacy. }\end{array}$ & Derak et al., 2018 \\
\hline & $\begin{array}{l}\text { Ownership } / \text { Clashing customary ownership and formal } \\
\text { regulating }\end{array}$ & $\begin{array}{l}\text { institutions forced local people off their lands for } \\
\text { the sake of a top-down implemented afforestation } \\
\text { project. This mediated negative outcomes for the } \\
\text { vulnerability of the local people. }\end{array}$ & 2018 \\
\hline
\end{tabular}

\section{Technical Factors}

Technical factors of intervention design were mostly reported to mediate positive outcomes. For example, case (Belgacem et al., 2018) reintroduced a traditional form of grazing, resting, and rotating to restore the rangelands in Southern Tunisia. Through different resting period lengths, the intervention showed how the technical element of time mediated ecological pathways outcomes in terms of degree of vegetation cover, density, and productivity. The intervention showed how the resting period should be adapted to precipitation and temperatures regimes, illustrating of how technical elements can mediate pathway outcomes.

\section{Social Factors}

Social factors identified by studies as mediating outcomes included education and inclusion of knowledge, values, and community members. Here, education refers to either external factors where the prior level of education mediated the outcome, e.g. Safari et al. (2019), or internal factors, as part of the intervention itself, e.g. Koutika (2019). Some studies recognised the importance of including local knowledge in intervention design for vulnerability reduction (Woldie \& Tadesse, 2019). Incorporation of local values in the project's implementation increased the acceptance of an intervention (Badola \& Hussain, 2005; Descheemaeker et al., 2010), which in turn is crucial for its adoption and overall success, thereby mediating vulnerability pathways the intervention addressed. Descheemaeker et al., (2010) highlight how social factors mediate outcomes, specifically how community inclusion and engagement facilitated an intervention in watershed management in Ethiopia. Specifically, this strengthened social adaptive capacity, building the capacity and confidence to deal climate change impacts as a community as well as taking control of issues regarding ownership of land. The high level of social acceptance facilitated the community-wide adoption of intervention, including the management of the watershed, ultimately influencing 
ecological pathways to vulnerability in terms of improved water flow and decreased soil degradation.

\section{Economic factors}

Economic mediating factors were less common but had substantial influence as mediating factors, where reported. Such factors were either internal to the intervention such as the level of income generation by the intervention (see for example Lin et al., 2019 and Baba \& Hack, 2019), or external to the intervention; relating to the economic status of community members prior to implementation of the NBS (see for example Lin et al., 2019 and Ali \& Rahut, 2020).

For example, in an intervention involving the introduction of community-based forestry institutions in Myanmar, Lin et al. (2019) highlights how high levels of poverty (external economic circumstances) constrained otherwise positive outcomes, thereby mediating overall outcomes. High levels of poverty prevented/hindered the participation, and inclusion in decision-making, of poorest households. In turn, decision-making for forest management and income generation/allocation were biased towards the wealthier households, creating a differential effect on vulnerability reduction. Furthermore, most activities related to the forest were voluntary, excluding economically marginalized households, in turn hindering the intervention's implementation and limiting its potential to reduce vulnerability. Hence, economic factors can mediate outcomes, in this case constraining the overall effectiveness of the intervention.

\section{Political factors}

Political mediating factors were directly related to historical, contextual, and intrinsic institutions and can be subdivided into issues of empowerment, ownership and access, conflict management, and management of land/ecosystem services (including who managers and how management occurs). Ownership and access refer to issues of rights, often issues of land tenure and clashing systems of ownership. Institutions mediated both positive and negative vulnerability outcomes. For example, the history of a reserve in Uganda was dominated by instability and colonial heritage, where colonial institutions clashed with customary land tenure systems (Edsted \& Carton, 2018). These conflicting institutions still formed the backdrop of the intervention, allowing afforestation for carbon sequestration on the lands of local people, despite the use of these areas by the local people based on customary land rights. These rights were not recognised in the intrinsic institutional mechanisms of the intervention, namely the top-down management driven by the Ugandan government and the Norwegian forestry company. As a result, local people lost their lands and 
livelihoods, most likely with increases in their vulnerability. Meanwhile Derak et al. (2018) showed that the lack of a conflict-mediation mechanism in an intervention involving forest restoration in Northern Morocco negatively influenced vulnerability outcomes by allowing inter-tribal competition to prevent different groups from accessing benefits and reducing the legitmacy of the intervention in the eyes of tribal organisations.

Some studies also recognised the influence of intrinsic institutions on vulnerability pathways involved in all types of $\mathrm{NbS}$ but especially in interventions focused on ecosystem management and protection. The intrinsic institutions that were identified mediated ecological as well as social pathways. Intrinsic institutions mediating ecological pathways often focused on informal agricultural institutions or influencing historical institutional change to shape social-ecological vulnerability. Both such aspects can be illustrated by the case of (Belgacem et al., 2018), where historical institutional change from traditional pastoralism to modernised agriculture in Tunisia led to extreme land degradation. The intervention focused on addressing land degradation through periodic rangeland exclosures and the implementation of traditional pastoralist techniques and management. The restoration of traditional institutions in combination with periodic exclosures, rather than exclosures alone, promoted the intervention's longevity, reducing the risk of regressing back towards unsustainably intensive land use and land deterioration.

In a similar way, several studies highlighted the influence of intrinsic institutions on social pathways. The case of Strauch et al. (2016) showed how historical institutional change from customary institutions to formal government institutions conflicted with social and cultural practices, thereby disempowering the community. The intervention, aiming to restore traditionally managed forests in Tanzania, focused on remediating ecological damage, while addressing issues of ownership and empowerment. Through joint ownership, co-management and land tenure rights, the intervention institutional mechanisms strengthened social, human, and economic capital. These effects directly shaped social pathways as the institutional empowerment enhanced social adaptive capacity and reduced social sensitivity.

\section{DISCUSSION}

Building on a systematic map of the effectiveness of nature-based interventions to address climate change (Chausson, Turner et al. 2020), we show how NbS act upon people's vulnerability through multiple pathways. We do this in a diversity of contexts by analysing 85 interventions from 66 studies, across 28 low- and lower-middle-income countries. The findings address a key knowledge gap on the 
effectiveness of NbS in reducing people's climate-related vulnerabilities in the rural global south. Through a mixed-methods approach we provide insights into whether and how NbS are effective.

Overall, the analysed cases of nature-based interventions showed overwhelmingly positive, vulnerability-reducing outcomes. Despite a quality appraisal process, we found few studies highlighting negative, mixed, or unclear effects on people's social-ecological vulnerability. There were important differential outcomes for particular social groups (such as wealthier, land-owning groups at the expense of poorer, landless groups) demonstrating how processes of marginalisation and empowerment condition who gains from nature-based vulnerability reduction efforts, a critically important line of research (cf. Eriksen et al., 2021; Ely, 2021). Whilst the assessment of whether NbS are effective or not provides useful evidence of their effectiveness across geographies and intervention types, perhaps the strongest contribution of the analysis is to reveal the diversity of social-ecological contexts in which NbS play a role and the manifold pathways in which NBS affect vulnerability. Both social and ecological dimensions of people's vulnerability were shaped by interventions through multiple pathways.

To our knowledge, this is the first framework clarifying how NbS shape vulnerability to climate impacts in social-ecological systems at the systematic level, contributing a social-ecological systems lens to vulnerability reduction (adaptation) pathways scholarship (Maru et al., 2014; Coloff et al., 2020). NbS most often shaped vulnerability through the pathway of reducing ecosystem sensitivity, such as where exclosures and the limited harvesting of grasses and roots restored land degradation, making the soil less sensitive to climatic stressors. Reduced social sensitivity, increased social adaptive capacity, and reduced ecological exposure, were represented in half to a third of all intervention-cases, respectively, making these significant pathways of vulnerability reduction. This shows how previous conceptualisations of social-ecological vulnerability may have miss important contributions of naturebased interventions. The least represented pathways were increasing ecological adaptive capacity and reducing social exposure.

It may be surprising that we identified social exposure as poorly represented, given previous literature demonstrating how ecosystems and NbS reduce people's exposure (Seddon et al. 2020b). There are several reasons for this that help to clarify our theoretical approach and contribution. First, we operationalized social pathways as independent of ecological pathways - i.e. specifically where an action intervenes on the social attributes of a social-ecological system. Second, in cases where people's overall exposure was affected, our dataset reveals that NbS intervene often principally reducing vulnerability to ecological assets that people value (such as productive ecosystems), in line 
with previous findings on social-ecological vulnerability (Cinner et al, 2012; Thiault et al., 2018). Finally, to avoid double counting, studies identifying indirect reductions to vulnerability of social attributes through direct reductions on ecological vulnerability were not coded also for the former.

We also find that intervention influence on ecological adaptive capacity is under reported in the literature. Specifically ecological adaptive capacity pertains to the 'diversity, heterogeneity, and connectedness of the ecosystem and the characteristics and conditions of its component species and habitats' (Seddon et al. 2020b). This may be because ecological monitoring incurs high financial and labor transaction costs. Alternatively, the importance of monitoring ecological capacity to capture how social-ecological systems reduce vulnerability may be underrecognized.

Our analysis also highlights mediating factors shaping the vulnerability reduction through NbS, most commonly, social, political, and technical factors. Moreover, results show the critical role of institutions in shaping how interventions are designed and implemented, and therefore, how they influence pathways of vulnerability reduction. Institutions are revealed to structure the conduct and context of an NbS. This complements research exploring how NbS are shaped by and expressed in people's agency and adaptation strategies (e.g. Palomo et al., 2021), by recognising their socialstructural characteristics, which can both constrain and enable 'nature-based' adaptation action. Confirming recent contributions to NbS literature at the general level, our findings show that access and tenure considerations are paramount in understanding how particular groups of people benefit from nature for adaptation, and that understanding the process of NbS design and implementation is crucial (Woroniecki, 2019; Mouk et al., 2021).

\section{Limitations and opportunities for future research}

Whilst we find convincing evidence the NbS can reduce people's vulnerability to climate change, few interventions represent the same configuration of variables, limiting generalizability across contexts. Some regions of the world (restricting the focus to Low- and Lower-Middle-Income Countries) are poorly represented, notably on the African continent, apart from a few East African countries. In Latin America, most countries were excluded, as few are lower income. These patterns can partly be accounted for by language barriers, as we excluded non-English studies (see Chausson et al., for further details). They are also indications of international inequalities in the distribution of funding and capacity for scientific research (see Chausson, Turner et al. 2020). 
Nevertheless, by combining descriptive statistics and qualitative analysis of rich intervention cases, we draw general patterns from the dataset, revealing the key role of contextual specificity for explaining outcomes. Importantly, our review demonstrates how NbS effectiveness and mediating factors vary across a range of geographies, habitats, types of interventions, and climatic impacts. Given this diversity, and with some caveats, we hold that the social-ecological vulnerability framework offers a robust post-hoc assessment frame to appraise the evidence to understand whether and how NbS shape vulnerability. Specifically, we offer a deeper understanding of the pathways to vulnerability reduction, helping to generate hypotheses and enabling more focussed research designs to examine the extent of vulnerability reduction in more specific circumstances. Such a context-sensitive approach situates us in the movement to a broader notion of 'nature's contributions to people' with its pluralistic approach to knowledge and recognition of local contexts and priorities (Kadykalo et al., 2019). Although we do not show the extent to which vulnerability is reduced, we show the range of ways in which interventions can shape vulnerability in specific contexts. It is especially important to conduct further research on the extent and limits of NbS effectiveness in the rural Global South, given the extreme nature of climate changes being experienced by many communities, and the ability of climate impacts to overwhelm adaptation actions, resulting in loss and damage, including to ecosystems (IPCCSR1.5).

Lastly, the analysis is limited by the perspectives and research designs of the studies included in the evidence map on which this analysis is based (Chausson, Turner et al. 2021). The scope/focus of included studies may hide other vulnerability pathways, in particular given the initial restriction of the map to studies explicitly linking a nature-based intervention with climate impact outcomes. Importantly, studies only focusing on intervention implementation, management or governance, were excluded where they did not report effects on climate impacts (e.g. effects on soil erosion, or surface water flooding). Therefore, social vulnerability pathways may be missed. Also, we are bound to follow causal inferences linking the intervention to vulnerability outcomes as they are reported in the studies captured. Other drivers beyond nature-based interventions may have been instrumental in delivering the vulnerability reduction benefits. Finally, studies may have omitted other social groups in the intervention's sphere of influence. As the scholarship on equity in relation to EbA shows, it is crucial to focus on how benefits are socially-disaggregated across different groups and how vulnerability may be redistributed between groups, including as part of NbS interventions (Atteridge and Remling, 2018 Eriksen et al., 2021). This is an important gap for further research.

\section{Contributions to research and practice}


Using NbS as an analytical concept, we address a key gap in understanding how to shape NbS to social and ecological contexts and capture how interactions between social-ecological systems and climate change impacts shape vulnerability for particular groups. In our assessment, the framework highlights the ways in which people's vulnerability to climate change is mediated by ecosystem structure and functioning, and complex social-ecological configurations produce adaptation benefits, an important gap in NbS scholarship. Such knowledge is crucial to design effective interventions. For policy and practice, recognizing how nbs effectiveness and mediating factors is context dependent is key to ensure policies are fit for purpose and practice is designed to suit the context in which NbS are implemented. Our analysis corroborates the notion nature-based solutions are co-produced through dynamic interactions between people and nature (Lavorel et al., 2020; Bruley et al., 2021; Weldon, Chausson et al., 2021).

The study contributes to several strands of contemporary sustainability science theory. It adds a socialecological dimension to work on adaptation pathways as developed by Coloff et al., (2021), Wise et al., (2014) as well as Ely (2022) in terms of pathways to sustainability. Adaptation pathways have been elaborated to draw attention to the various ways that societies respond to environmental change over time, emphasising the key bifurcation points at which a given system might go in a certain direction (and not in another direction) (Coloff et al., 2021). Although lacking a temporally-explicit focus, we complement this understanding by shedding light on how NbS for adaptation influence a given socialecological context. We draw attention to the political, social, and institutional characteristics of interventions mediating adaptation pathways (Eriksen and Lind, 2009; Woroniecki et al., 2020). The pathways to sustainability approach offer insights into the political character of adaptation processes and how such pathways can have differential costs and benefits for different groups, corroborating the need to focus on power relations permeating $\mathrm{NbS}$ and the contexts in which they intervene (Ensor et al., 2019). Closer links to these other pathways might result in longer-term analyses attempting to understand how people make use of NbS to confront climate risks over time, and how these attempts feedback on the contextual conditions of a given system (cf. Hoque et al., 2018).

Through our analysis, we provide a finer-grain focus on pathways through which nature-based interventions shape vulnerability, providing empirical evidence for how NbS intervene in a system to influence social or ecological exposure, sensitivity, or adaptive capacity. Further case study and metaanalytical research could focus more specifically on these pathways, especially the factors that mediate their synergies, interactions and trade-offs, and how NbS are shaped in specific regions, and contribute to transformative change across landscapes for different groups (Nesshöver et al., 2017). 
Finally, we show how institutions form part of the historical and contemporary context in which NbS intervene, and how they mediate success. This evidence supports the growing awareness of the institutional character of ecosystem-based as well as other kinds of adaptation (Agarwal et al., 2008; Eriksen and Lind, 2009). Further work could explore how institutional changes may impede as well as facilitate nature-based adaptation in different contexts.

The study also offers useful considerations for practitioners, making clear that outcomes are multidimensional, affecting both social and ecological dimensions of a given system to mediate vulnerability outcomes. We show that a narrow focus on technical mediating factors is likely to miss the key role of political and social factors in influencing intervention outcomes (Osaka et al., 2021). Similarly, narrowly focusing on a system's ecological dimensions may sideline valuable social dimensions of adaptation (Diaz et al., 2021). Thus, our results clearly show how NbS are not synonymous with 'ecosystem services', but rather represent coordinated projects involving people and nature working towards specific societal challenges (Lavorel et al., 2019; Bruley et al., 2021; Welden, Chausson. et al., 2021).

NbS have largely been recognised for their ability to deliver 'co-benefits' that engineered approaches may not be able to provide. Based on our analysis, such co-benefits (e.g. Woroniecki et al., 2019) play a crucial role in reducing social-ecological vulnerability. To understand this more holistic contribution to people's vulnerability contexts means shifting attention from the climate impacts per se, and more into the components of vulnerability such as sensitivity and adaptive capacity (O Brien et al., 2007; Singh et al., 2021). This highlights the need to consider vulnerability in more integrated ways, especially in the global south, whilst also keeping in mind issues of access, equity, and the complexity of social-ecological systems (Olsson et al., 2014; Pinho et al., 2014; Hoque et al., 2018;). For example, Bhowmik et al., (2021) how different shocks and stresses function in the coastal small-scale marine fisheries SES of Bangladesh, demonstrating the multiple dimensions of vulnerability.

Our analysis does not claim to comprehensively shed light on how NbS might address the social and political root causes of vulnerability. Instead, we highlight how vulnerability is best understood as the property of a system, in which social and ecological vulnerability interact. An integrated approach that goes beyond narrow indicators or climate impacts can be further through genuine participatory approaches with local stakeholders and rightsholders, moving beyond technical assessments of climate risk and hazards. It remains crucial to understand how vulnerability is shaped in specific places, 
and for specific groups (Quealy and Yates, 2021). Without addressing root causes, NbS may only superficially addresses the symptoms of deeper, lingering problems, potentially side-lining efforts to remediate the deeper causes of vulnerability. Designing effective intervention rests on recognizing how vulnerability is shaped by a broader social-ecological processes (e.g. adaptive capacity), beyond any particular project or intervention (Eriksen et al., 2015). For example, Mehta et al., have explored these issues in relation to marginalised groups in India, exploring the key role of agency and the coproduction of social-ecological knowledge in integrated adaptation and developed responses (2021). By studying the effectiveness of NbS in Bangladesh, Smith et al. (under review) also identify four enabling factors, namely government's policy support to NbS; participatory delivery; strong and transparent governance; and secured finance and land tenure, to maximize NbS benefits and manage trade-offs. Indeed, an awareness of social, and ecological trade-offs, including trade-offs between key core outcomes of NbS (e.g. biodiversity conservation, climate mitigation, and livelihood security) would facilitate a greater understanding of the promise and pitfalls of these approaches. We would especially urge scholars from the Global South to undertake such research, since perspectives from the global South, which have been missing and under-recognised in climate research, are vital to understand the global and regional imperatives and complexities involved in effectively reducing vulnerability.

\section{Conclusion}

Nature-based solutions are called upon to address global societal imperatives such as biodiversity and climate crises. The evidence for adaptation benefits from nature-based approaches is limited mostly to case studies, and a systematic appraisal of the evidence base has so far been lacking. Here we analysed the contributions of nature-based interventions to climate change vulnerability in the rural global south by collating a wide variety of case-based evidence. Most of the people whose vulnerability is addressed by the interventions have nature-dependent livelihoods that make them especially vulnerable to the climate crisis. We paid attention to the vulnerability contexts of these people, and, to counter a previous blindspot of nature-based solutions to their social aspects, we focused on how different types of institutions shape 'nature-based' approaches.

This study highlights the need to carefully consider the context specificity to unpack how NbS reduce vulnerability and for whom. We suggest that future research pays close attention to intervention and vulnerability contexts, including local needs and adaptation priorities, whilst not ignoring the climate risks to ecosystems themselves. Holding these elements together in study designs is crucial, so that NbS can be effective, equitable and sustainable.. We showed how effectiveness is strongly mediated 
by social and political mediating factors, besides the technical factors which usually get the most attention, reiterating the need for interdisciplinary approaches to understanding NbS and links to development processes (Schipper et al., 2016). Lastly, we hope that this study provides a useful starting point for more contributions from researchers from the Global South, whose insights, experiences, and knowledges are so crucial to understanding and addressing vulnerability contexts in this neglected part of the world.

\section{REFERENCES}

Adger, W. N., Eakin, H. and Winkels, A. (2009) 'Nested and teleconnected vulnerabilities to environmental change', Frontiers in Ecology and the Environment. Wiley-Blackwell, 7(3), pp. 150157. doi: $10.1890 / 070148$.

Agrawal, Arun; McSweeney, Catherine; Perrin, Nicolas. 2008. Local Institutions and Climate Change Adaptation. Social Development Notes; No. 113. World Bank, Washington, DC. (C) World Bank. https://openknowledge.worldbank.org/handle/10986/11145

Atteridge, A. and Remling, E. (2018), Is adaptation reducing vulnerability or redistributing it?. WIREs Clim Change, 9: e500.

Bhowmik, J., Selim, S.A., Irfanullah, H.Md., Shuchi, J.S., Sultana, R., \& Ahmed, S.G. (2021) Resilience of Small-Scale Marine Fishers of Bangladesh Against the COVID-19 Pandemic and the 65-Day Fishing Ban. Marine Policy, 134, 104794. https://doi.org/10.1016/j.marpol.2021.104794

Brink, E., Aalders, T., Ádám, D., Feller, R., Henselek, Y., Hoffmann, A., ... Wamsler, C. (2016). Cascades of green: A review of ecosystem-based adaptation in urban areas. Global Environmental Change, 36, 111-123. https://doi.org/10.1016/J.GLOENVCHA.2015.11.003

Bruley, E., B. Locatelli, and S. Lavorel. 2021. Nature's contributions to people: coproducing quality of life from multifunctional landscapes. Ecology and Society 26(1):12. https://doi.org/10.5751/ES12031-260112

Colloff, M. J., Wise, R. M., Palomo, I., Lavorel, S., \& Pascual, U (2020) Nature's contribution to adaptation: insights from examples of the transformation of social-ecological systems, Ecosystems and People, 16:1, 137-150, DOI: 10.1080/26395916.2020.1754919

Daw, T. M., C. C. Hicks, K. Brown, T. Chaigneau, F. A. Januchowski-Hartley, W. W. L. Cheung, S. Rosendo, B. Crona, S. Coulthard, C. Sandbrook, C. Perry, S. Bandeira, N. A. Muthiga, B. SchulteHerbrüggen, J. Bosire, and T. R. McClanahan. 2016. Elasticity in ecosystem services: Exploring the variable relationship between ecosystems and human well-being. Ecology and Society 21(2).

Depietri., Y (2020) The social-ecological dimension of vulnerability and risk to natural hazards Sustainability Science Vol. 15, Iss. 2, (Mar 2020): 587-604. DOI:10.1007/s11625-019-00710-y

Díaz, S., U. Pascual, M. Stenseke, B. Martín-López, R. T. Watson, Z. Molnár, R. Hill, K. M. A. Chan, I. A. Baste, K. A. Brauman, S. Polasky, A. Church, M. Lonsdale, A. Larigauderie, P. W. Leadley, A. P. E. Van Oudenhoven, F. Van Der Plaat, M. Schröter, S. Lavorel, Y. Aumeeruddy-Thomas, E. Bukvareva, K. Davies, S. Demissew, G. Erpul, P. Failler, C. A. Guerra, C. L. Hewitt, H. Keune, S. Lindley, and Y. Shirayama. 2018. Assessing nature's contributions to people: Recognizing culture, and diverse sources of knowledge, can improve assessments. Science 359(6373):270-272

Doswald, N., R. Munroe, D. Roe, a Giuliani, I. Castelli, J. Stephens, I. Möller, T. Spencer, B. Vira, and H. Reid. 2014. Effectiveness of ecosystem-based approaches for adaptation: review of the evidence-base. Climate and Development 
Du S, Scussolini P, Ward PJ, et al (2020) Hard or soft flood adaptation? Advantages of a hybrid strategy for Shanghai. Glob Environ Chang 61:102037. doi: 10.1016/j.gloenvcha.2020.102037

Ely, 2022, Transformative Pathways to Sustainability; Learning Across Disciplines, Cultures and Contexts. Routledge, London.

Ensor, J. E., P. Wennström, A. Bhatterai, A. J. Nightingale, S. Eriksen, and J. Sillmann. 2019. Asking the right questions in adaptation research and practice: Seeing beyond climate impacts in rural Nepal. Environmental Science and Policy 94(February):227-236.

Eriksen, S. and J. Lind, 2009: Adaptation as a political process: adjusting to drought and conflict in Kenya's drylands. Environmental Management, 43(5), 817-835.

Eriksen, S., Schipper, E. L. F., Scoville-Simonds, M., Vincent, K., Adam, H. N., Brooks, N., Harding, B., Khatri, D., Lenaerts, L., Liverman, D., Mills-Novoa, M., Mosberg, M., Movik, S., Muok, B., Nightingale, A., Ojha, H., Sygna, L., Taylor, M., Vogel, C., \& West, J. J. (2021). Adaptation interventions and their effect on vulnerability in developing countries: Help, hindrance or irrelevance? World Development, 141, [105383]. https://doi.org/10.1016/j.worlddev.2020.105383

Fischer, J., T. A. Gardner, E. M. Bennett, P. Balvanera, R. Biggs, S. Carpenter, T. Daw, C. Folke, R. Hill, T. P. Hughes, T. Luthe, M. Maass, M. Meacham, A. V. Norström, G. Peterson, C. Queiroz, R. Seppelt, M. Spierenburg, and J. Tenhunen. 2015. Advancing sustainability through mainstreaming a socialecological systems perspective. Current Opinion in Environmental Sustainability 14:144-149.

Gallopín, G. C. (2006) 'Linkages between vulnerability, resilience, and adaptive capacity', Global Environmental Change. Pergamon, 16(3), pp. 293-303. doi: 10.1016/j.gloenvcha.2006.02.004.

Hoque, S. F., C. Quinn, and S. Sallu. 2018. Differential livelihood adaptation to socialecological change in coastal Bangladesh. Regional Environmental Change 18(2):451-463

Huntington, Samuel P., The Clash of Civilizations and the Remaking of World Order, New York, Simon \& Schuster, 1996 ISBN 0-684-84441-9

IPBES. 2019. Summary for policymakers of the global assessment report on biodiversity and ecosystem services of the Intergovernmental Science-Policy Platform on Biodiversity and Ecosystem Services. S. Díaz, J. Settele, E. S. Brondízio E.S., H. T. Ngo, M. Guèze, J. Agard, A. Arneth, P. Balvanera, K. A. Brauman, S. H. M. Butchart, K. M. A. Chan, L. A. Garibaldi, K. Ichii, J. Liu, S. M. Subramanian, G. F. Midgley, P. Miloslavich, Z. Molnár, D. Obura, A. Pfaff, S. Polasky, A. Purvis, J. Razzaque, B. Reyers, R. Roy Chowdhury, Y. J. Shin, I. J. Visseren-Hamakers, K. J. Willis, and C. N. Zayas (eds.). IPBES secretariat, Bonn, Germany. 56 pages.

IPCC 2014. IPCC Fifth Assessment Synthesis Report. Climate Change 2014: Synthesis Report. Contribution of Working Groups I, II and III to the Fifth Assessment Report of the Intergovernmental Panel on Climate Change.

IPCC AR6 forthcoming,

IPCC SRCCL 2019. Special Report on Climate Change and Land. Intergovernmental Panel on Climate Change.

IPCC, 2014: Climate Change 2014: Impacts, Adaptation, and Vulnerability. Part A: Global and Sectoral Aspects. Contribution of Working Group II to the Fifth Assessment Report of the Intergovernmental Panel on Climate Change [Field, C.B., V.R. Barros, D.J. Dokken, K.J. Mach, M.D. Mastrandrea, T.E. Bilir, M. Chatterjee, K.L. Ebi, Y.O. Estrada, R.C. Genova, B. Girma, E.S. Kissel, A.N. Levy, S. MacCracken, P.R. Mastrandrea, and L.L.White (eds.)]. Cambridge University Press, Cambridge, United Kingdom and New York, NY, USA, 1132 pp.

IPCCSR1.5 (Masson-Delmotte, V., P. Zhai, H.-O. Pörtner, D. Roberts, J. Skea, P.R. Shukla, A. Pirani, W. Moufouma-Okia, C. Péan, R. Pidcock, S. Connors, J.B.R. Matthews, Y. Chen, X. Zhou, M.I. Gomis, E. 
Lonnoy, T. Maycock, M. Tignor, and T. Waterfield (eds.)) Global Warming of $1.5^{\circ} \mathrm{C}$. An IPCC Special Report on the impacts of global warming of $1.5^{\circ} \mathrm{C}$ above pre-industrial levels and related global greenhouse gas emission pathways, in the context of strengthening the global response to the threat of climate change, sustainable development, and efforts to eradicate poverty. Intergovernmental Panel on Climate Change.

J.E. Cinner, T.R. McClanahan, N.A.J. Graham, T.M. Daw, J. Maina, S.M. Stead, A. Wamukota, K. Brown, Ö. Bodin, (2012) Vulnerability of coastal communities to key impacts of climate change on coral reef fisheries, Global Environmental Change, Volume 22, Issue 1,

Jones, H. P., D. G. Hole, and E. S. Zavaleta. 2012. Harnessing nature to help people adapt to climate change. Nature Climate Change 2(7):504-509.

Kadykalo, A. N., M. D. López-rodriguez, J. Ainscough, N. Droste, H. Ryu, G. Ávila-flores, S. Le, M. C. Muñoz, S. Rana, P. Sarkar, K. J. Sevecke, and Z. V Harmáčková. 2019. Disentangling "ecosystem services" and "nature's contributions to people". Ecosystems and People 15(1):269-287.

Krasny, M. E., A. Russ, K. G. Tidball, and T. Elmqvist. 2014. Civic ecology practices: Participatory approaches to generating and measuring ecosystem services in cities. Ecosystem Services 7:177186

Lavorel, S., M.J. Colloff, B. Locatelli, R. Gorddard, S.M. Prober, M. Gabillet, C. Devaux, D. Laforgue, V. Peyrache-Gadeau (2019), Mustering the power of ecosystems for adaptation to climate change Environ. Sci. Policy, 92 pp. 87-97

Lavorel, S., B. Locatelli, M.J. Colloff, E. Bruley (2020), Co-producing ecosystem services for adapting to climate change. Philos. Trans. Biol. Sci., 375 Article 20190119

Mahoney, J., Thelen, K., (2010) Explaining Institutional Change: Ambiguity, Agency, and Power. Cambridge University Press.

Manuel-Navarrete, Pelling, and Redclift, 2011 'Critical Adaptation to Hurricanes in the Mexican Caribbean: Development Visions, Governance Structures, and Coping Strategies'. Glob. Environ. Chang. Volume 21, Issue 1, February 2011, Pages 249-258

Maru, Y. T., M. Stafford Smith, A. Sparrow, P. F. Pinho, and O. P. Dube. 2014. A linked vulnerability and resilience framework for adaptation pathways in remote disadvantaged communities. Global Environmental Change 28:337-350.

Mehta, L,m S Srivastava, S Movik, HN Adam, R D'Souza... (2021) Transformation as praxis: responding to climate change uncertainties in marginal environments in South Asia. - Current Opinion in Environmental Sustainability, Volume 49, April 2021, Pages 110-117

Mercer, J., I. Kelman, B. Alfthan, and T. Kurvits. 2012. Ecosystem-based adaptation to climate change in caribbean small island developing states: Integrating local and external knowledge. Sustainability 4(8):1908-1932.

Mouk, B O, Mosberg, M, Hallstrom Eriksen, S E, Ong'ech, D O (2021) The politics of forest governance in a changing climate: Political reforms, conflict and socio-environmental changes in Laikipia, Kenya. Forest Policy Econ 132: 102590

Munang, R., I. Thiaw, K. Alverson, M. Mumba, J. Liu, and M. Rivington. 2013. Climate change and Ecosystem-based Adaptation: A new pragmatic approach to buffering climate change impacts. Current Opinion in Environmental Sustainability 5(1):67-71.

Munang, R., J. Andrews, K. Alverson, and D. Mebratu. 2014. Harnessing Ecosystem-based Adaptation To Address the Social Dimensions of Climate Change. Environment: Science and Policy for Sustainable Development 56(1):18-24. 
Nesshöver, C., T. Assmuth, K. N. Irvine, G. M. Rusch, K. A. Waylen, B. Delbaere, D. Haase, L. JonesWalters, H. Keune, E. Kovacs, K. Krauze, M. Külvik, F. Rey, J. van Dijk, O. I. Vistad, M. E. Wilkinson, and $\mathrm{H}$. Wittmer. 2017. The science, policy and practice of nature-based solutions: An interdisciplinary perspective. Science of the Total Environment 579:1215-1227

North, Douglass C. (1991) “Institutions.” The Journal of Economic Perspectives 5, no. 1: 97-112. http://www.jstor.org/stable/1942704.

O'Brien, K., S. Eriksen, L. P. Nygaard, and A. Schjolden. 2007. Why different interpretations of vulnerability matter in climate change discourses. Climate Policy 7(1):73-88.

Olsson, L., M. Opondo, P. Tschakert, A. Agrawal, S. H. Eriksen, S. Ma, L. N. Perch, and S. A. Zakieldeen. 2014. Livelihoods and poverty. Pages 793-832 in C. B. Field, V. R. Barros, D. J. Dokken, K. J. Mach, M. D. Mastrandrea, T. E. Bilir, M. Chatterjee, K. L. Ebi, Y. O. Estrada, R. C. Genova, B. Girma, E. S. Kissel, A. N. Levy, S. MacCracken, P. R. Mastrandrea, and L. L. White, editors. Climate change 2014: impacts, adaptation and vulnerability. Part A: global and sectoral aspects.

Contribution of working Group II to the Fifth Assessment Report of the Intergovernmental Panel on Climate Change. Cambridge University Press, Cambridge, UK.

Osaka, S., Bellamy, R., Castree, N. (2021) Framing "nature-based" solutions to climate change. WIRES Clim Change.; 12:e729.

Ostrom, E. (2005). Understanding institutional diversity. Princeton University Press, Princeton, New Jersey, USA.

P. Smith, K. Calvin, J. Nkem, D. Campbell, F. Cherubini, G. Grassi, V. Korotkov, A. Le Hoang, S. Lwasa, P. McElwee (2020) Which practices co-deliver food security, climate change mitigation and adaptation, and combat land degradation and desertification? Glob. Chang. Biol., 26 pp. 1532-1575

Paavola, Jouni \& Adger, W.. (2006). Fair Adaptation to Climate Change. Ecological Economics. 56. 594-609. 10.1016/j.ecolecon.2005.03.015.

Palomo, I., Locatelli, B., Otero, I., Colloff, M., Crouzat, E., Cuni-Sanchez, A., Gómez-Baggethun, E., González-García, A., Grêt-Regamey, A., Jiménez-Aceituno, A., Martín-López, B., Pascual, U., ZafraCalvo, N., Bruley, E., Fischborn, M., Metz, R., \& Lavorel, S. (2021). Assessing nature-based solutions for transformative change. One Earth, 4, 1-12. https://doi.org/10.1016/j.oneear.2021.04.013

Partelow, S., and K. J. Winkler. 2016. Interlinking ecosystem services and Ostrom's framework through orientation in sustainability research. Ecology and Society 21(3):27.

Pinho, P. F., G. Patenaude, J. P. Ometto, P. Meir, P. M. Toledo, A. Coelho, and C. E. F. Young. 2014 b. Ecosystem protection and poverty alleviation in the tropics: Perspective from a historical evolution of policy-making in the Brazilian Amazon. Ecosystem Services 8:97-109

Pinho, P. F., J. A. Marengo, and M. S. Smith. 2014a. Complex socio-ecological dynamics driven by extreme events in the Amazon. Regional Environmental Change 15(4):643-655.

Polishchuk, Y., and F. Rauschmayer. 2012. Beyond "benefits"? Looking at ecosystem services through the capability approach. Ecological Economics 81:103-111

Pörtner, H.O., Scholes, R.J., Agard, J., Archer, E., Arneth, A., Bai, X., Barnes, D., Burrows, M., Chan, L., Cheung, W.L., Diamond, S., Donatti, C., Duarte, C., Eisenhauer, N., Foden, W., Gasalla, M. A., Handa, C., Hickler, T., Hoegh-Guldberg, O., Ichii, K., Jacob, U., Insarov, G., Kiessling, W., Leadley, P., Leemans, R., Levin, L., Lim, M., Maharaj, S., Managi, S., Marquet, P. A., McElwee, P., Midgley, G., Oberdorff, T., Obura, D., Osman, E., Pandit, R., Pascual, U., Pires, A. P. F., Popp, A., ReyesGarcía, V., Sankaran, M., Settele, J., Shin, Y. J., Sintayehu, D. W., Smith, P., Steiner, N., Strassburg, B., Sukumar, R., Trisos, C., Val, A.L., Wu, J., Aldrian, E., Parmesan, C., Pichs-Madruga, R., Roberts, D.C., Rogers, A.D., Díaz, S., Fischer, M., Hashimoto, S., Lavorel, S., Wu, N., Ngo, H.T. 2021. IPBES-IPCC co- 
sponsored workshop report on biodiversity and climate change; IPBES and IPCC. DOI:10.5281/zenodo.4782538.

Quealy, H.M., and Yates, J. S., (2021) Situated adaptation: Tackling the production of vulnerability through transformative action in Sri Lanka's Dry Zone, Global Environmental Change, Volume 71, 102374,

R.M. Wise, I. Fazey, M. Stafford Smith, S.E. Park, H.C. Eakin, E.R.M. Archer Van Gardenen, B. Campbell (2014) Reconceptualising adaptation to climate change as part of pathways of change and response. Glob. Environ. Chang. Part A, 28 (2014), pp. 325-336

Ribot, J. 2010. Vulnerability does not fall from the sky: Towards multi-scale, pro-poor climate policy. Social dimensions of climate change: equity and vulnerability in a warming world page 319 . The World Bank, Washington.

Roy, J., P. Tschakert, H. Waisman, S. Abdul Halim, P. Antwi-Agyei, P. Dasgupta, B. Hayward, M. Kanninen, D. Liverman, C. Okereke, P.F. Pinho, K. Riahi, and A.G. Suarez Rodriguez, 2018: Sustainable Development, Poverty Eradication and Reducing Inequalities. In: Global Warming of $1.5^{\circ} \mathrm{C}$. An IPCC Special Report on the impacts of global warming of $1.5^{\circ} \mathrm{C}$ above pre-industrial levels and related global greenhouse gas emission pathways, in the context of strengthening the global response to the threat of climate change, sustainable development, and efforts to eradicate poverty [Masson-Delmotte, V., P. Zhai, H.-O. Pörtner, D. Roberts, J. Skea, P.R. Shukla, A. Pirani, W. Moufouma-Okia, C. Péan, R. Pidcock, S. Connors, J.B.R. Matthews, Y. Chen, X. Zhou, M.I. Gomis, E. Lonnoy, T. Maycock, M. Tignor, and T. Waterfield (eds.)]. In Press

Schipper, E.L.F., Thomalla, F., Vulturius, G., Davis, M. and Johnson, K. (2016), "Linking disaster risk reduction, climate change and development", International Journal of Disaster Resilience in the Built Environment, Vol. 7 No. 2, pp. 216-228. https://doi.org/10.1108/IJDRBE-03-2015-0014

Seddon, N., \& Chausson, A., \& Berry, P., Girardin, C., Smith, A \& Turner, B (2020). Understanding the value and limits of nature-based solutions to climate change and other global challenges. Philosophical Transactions of the Royal Society B: Biological Sciences. 375. 20190120. 10.1098/rstb.2019.0120.

Seddon, N., Daniels, E., Davis, R., Chausson, A., Harris, R., Hou-Jones, X., Huq, S., Kapos, V., Mace, G. M., Rizvi, A. R., Reid, H., Roe, D., Turner, B., Wicander, S. (2020). Global recognition of the importance of nature-based solutions to the impacts of climate change. Global Sustainability, 3, E15. doi:10.1017/sus.2020.8

Seddon, N., Smith, A., Smith, P., Key, I., Chausson, A., Girardin, C., House, J., Srivastava, S. and Turner, B. (2021), Getting the message right on nature-based solutions to climate change. Glob. Change Biol., 27: 1518-1546.

Simpson, N. P., Schmidt, D. N., Trisos, C. H., \& al., E. (2021). A framework for complex climate change risk assessment. One Earth, 4(4), 489-501. https://doi.org/10.1016/j.oneear.2021.03.005

Singh C, lyer S, New MG, Few R, Kuchimanchi B, Segnon AC, Morchain D. 2021. Interrogating 'effectiveness' in climate change adaptation: 11 guiding principles for adaptation research and practice. Climate and Development

Smit, B., \& Wandel, J. (2006). Adaptation, adaptive capacity and vulnerability. Global Environmental Change, 16(3), 282-292. https://doi.org/10.1016/J.GLOENVCHA.2006.03.008

Smith et al., under peer review Frontiers in Environmental Science.

Thiault, L., Marshall, P., Gelcich, S., Collin, A., Chlous, F., \& Claudet, J. (2018). Mapping socialecological vulnerability to inform local decision making. Conservation biology : the journal of the Society for Conservation Biology, 32(2), 447-456. https://doi.org/10.1111/cobi.12989 
Welden, EA, Chausson, A, Melanidis, MS. Leveraging Nature-based Solutions for transformation: Reconnecting people and nature. People and Nature. 2021; 3: 966- 977.

https://doi.org/10.1002/pan3.10212

World Bank. (2020). Country and lending groups. Retrieved from https://datahelpdesk.worldbank.org/knowledgebase/articles/906519-world-bank-countryand-lending-groups

Woroniecki, S., 2019. "Enabling Environments? Examining Social Co-Benefits of Ecosystem-Based Adaptation to Climate Change in Sri Lanka" Sustainability 11, no. 3: 772. https://doi.org/10.3390/su11030772

Woroniecki, S., C. Wamsler, and E. Boyd. 2019. The promises and pitfalls of ecosystem-based adaptation to climate change as a vehicle for social empowerment. Ecology and Society 24(2):4.

Young, O. (1986). International Regimes: Toward a New Theory of Institutions. World Politics, 39(1), 104-122. doi:10.2307/2010300 